Anuario de Estudios Medievales

42/2, julio-diciembre de 2012, pp. 567-599

ISSN 0066-5061

doi:10.3989/aem.2012.42.2.13

\title{
LAS ENCUADERNACIONES MUDÉJARES TOLEDANAS CON MOTIVO CENTRAL DE LA CATEDRAL DE TOLEDO ${ }^{1}$
}

\author{
TOLEDO'S MUDEJAR BOOKBINDINGS \\ WITH CENTRAL MOTIF OF THE CATHEDRAL OF TOLEDO
}

\author{
ANTONIO CARPALLO BAUTISTA \\ Universidad Complutense de Madrid
}

\begin{abstract}
Resumen: La Biblioteca Capitular de la Catedral de Toledo dispone entre sus fondos de un grupo de encuadernaciones mudéjares con motivos decorativos centrales realizadas por artesanos durante el siglo XV. Este trabajo nos señala la existencia de diferentes talleres que realizaron encargos para la catedral mediante el estudio de las estructuras decorativas de las tapas y lomos, los elementos decorativos individuales empleados, la construcción y decoración de las cabezadas, los broches metálicos y bordados, así como la identificación de los emblemas heráldicos que aparecen en los primeros folios de los volúmenes.
\end{abstract}

Palabras clave: encuadernación mudéjar con motivo central; catedral de Toledo; siglo XV; encuadernaciones toledanas.

\begin{abstract}
The Capitular Library of Toledo Cathedral has among its collection a group of Mudejar bindings with decorative central motives realized by craftsmen during the 15 th century. This work indicates the existence of different workshops that realized orders for the cathedral by means of the study of the decorative structures of the boards and spines, the individual decorative elements used, the construction and decoration of the headbands, the metallic and embroidered clasps, as well as the identification of the heraldic emblems that appear on the first folios of the volumes.
\end{abstract}

Keywords: Mudejar bookbindings with central motif; cathedral of Toledo; 15 th century; bindings' Toledo.

\section{SUMARIO}

1. Introducción.- 2. Encuadernaciones con palmetas y círculos aspados.- 3. Encuadernaciones con flores de lis y círculos aspados.- 4. Encuadernaciones con bastoncillos curvos y rectos y eses inclinadas.- 5. Encuadernación con robos de lados cóncavos y lazos simples rectos.6. Conclusiones.- 7. Bibliografía citada.

1 Este trabajo forma parte de los resultados obtenidos dentro del Proyecto de Investigación Santander/Central-Complutense titulado Las encuadernaciones de la Catedral de Toledo: catalogación y difusión (PR41/06-14969), para el periodo 2007-2008 y finalizado en junio de 2009 y de las líneas de investigación de Grupo BIBLIOPEGIA: grupo de investigación sobre encuadernación y el libro antiguo (941369) de la Universidad Complutense de Madrid. En este proyecto de investigación han participado Antonio Carpallo Bautista, como investigador principal, Esther Burgos Bordonau, Adelina Clausó García, Ana Belén Sánchez Prieto, Arsenio Sánchez Hernampérez y Juan Antonio Yeves Andrés como investigadores. Agradecer al prof. Dr. José María de Francisco Olmos la ayuda prestada en la identificación y descripción de los escudos heráldicos. 


\section{INTRODUCCIÓN}

Desde la creación del Cabildo Primado de la Catedral de Toledo a finales del siglo XI los fondos de su Archivo y Biblioteca Capitulares han ido creciendo generados por el propio Cabildo pero también mediante donaciones, en su mayoría de clérigos como el arzobispo don Pedro Tenorio (1328-1399) quien sufragó la construcción de la biblioteca y cedió sus manuscritos creándose lo que conocemos hoy en día como el Antiguo Fondo Toledano, a la que pertenecen las encuadernaciones estudiadas en este trabajo. Otros donantes ilustres fueron el cardenal Francisco Javier de Zelada (1717-1801) y el cardenal y arzobispo de Toledo Francisco Antonio de Lorenzana (1722-1800) que donaron parte de sus bibliotecas particulares a la catedral, y que forman parte de los Fondo Zelada y Fondo Lorenzana actualmente.

Entre las aportaciones españolas más importantes a la historia de la encuadernación están las encuadernaciones mudéjares, que se realizaron en la península Ibérica entre los siglos XIII y XVI por artesanos musulmanes denominándose también estilo hispano-árabe o hispano-morisco. De la serie custodiada en la Catedral de Toledo existen diferentes procedencias: toledanas, con exquisitas lacerías y totalmente cuajadas de pequeños hierrecillos; italianas, realizadas a finales del siglo XV, posiblemente napolitanas; y otro grupo más variado con obras de procedencias diversas.

Ya existen varios estudios ${ }^{2}$ sobre encuadernaciones mudéjares pero hasta la fecha no se había realizado uno sobre las encuadernaciones mudéjares toledanas custodiadas en la Catedral de Toledo.

Dentro del grupo de encuadernaciones mudéjares con motivo central encontramos una variedad extraordinaria, destacando el grupo con una estrella central, aunque también encontramos motivos centrales como círculos, rombos, cruces, cuadrados, triángulos entre otras figuras geométricas simples o dobles, y con un origen sobre todo español aunque también aparecen estructuras decorativas y motivos italianos.

Entre las encuadernaciones mudéjares con motivo central, hemos encontrado once con una estrella en el centro, realizadas en talleres toledanos durante el siglo XV, que pertenecieron al arzobispo Pedro Tenorio (1376-1399), y otras italianas, seguramente varias de ellas napolitanas, sobre todo las ocho donde se emplean como motivo característico una "roseta", junto a otras nueve con estructuras decorativas diferentes y que tienen estructuras decorativas análogas a las de la biblioteca de Alfonso el Magnánimo (1442-1458) y continuada por su sucesor Fernando I, rey de Nápoles (1458-1494). Nuestro trabajo se centra en el estudio exhaustivo de las encuadernaciones realizadas en Toledo por artesanos laicos, ya que la propia Catedral carecía de taller de encuadernación y todos los trabajos eran encargados a artesanos externos, como se indica en las anotaciones de los libros de Obra y Fábrica de la Catedral donde se señalan diferentes pagos realizados a encuadernadores como Maestre Arnao, "librero" del que tenemos noticias por pagos de encuadernaciones entre 1425 y 1432; Miguel Sánchez, racionero ${ }^{3}$ de la catedral con una anotación en 1425; Luis, lector en la iglesia de Toledo con una anotación en 1431; Juan González y Pedro Sánchez, "cantor, escribano de libros", con anotaciones en 1432; Diego Sánchez, "librero" con

2 J. Ainaud, Encuadernación; I. Álvaro, Encuadernaciones mudéjares; A. Carpallo, Estudio de las encuadernaciones; A. Carpallo, E. Burgos, Las encuadernaciones mudéjares; F. Hueso, Exposición de encuadernaciones españolas; M. López, La encuadernación española; V. Méndez, Encuadernación mudéjar; J. Méndez, La encuadernación mudéjar; R. Miquel y Planas, Restauración del Arte hispano-árabe .

${ }^{3}$ Racionero de la Catedral, es decir, prebendado que tenía ración en la iglesia, a cambio de realizar trabajos artísticos para la institución que le albergaba. 
una anotación en 1448; Sancho Rodríguez de Toledo, "librero" con anotaciones varias entre 1453 y 1475; Pedro, encuadernador con una anotación del año 1475 y Gonzalo Rodríguez con anotaciones entre los años 1493 y 1508.

\section{ENCUADERNACIONES CON PALMETAS Y CÍRCULOS ASPADOS}

Las primeras seis encuadernaciones tienen una estructura decorativa muy similar, donde se emplean los mismos hierros para la ornamentación de las tapas y de los lomos, como rombos anudados, círculos aspados cordiformes o no, dobles palmetas, que muy posiblemente fueron realizadas en la primera mitad del siglo XV en un mismo taller o talleres toledanos de la misma época donde se empleaban los mismos esquemas y motivos decorativos. Sabemos que todas las obras fueron realizadas con anterioridad al siglo XV, incluso de alguna de ellas quienes fueron sus propietarios hasta que llegaron a la Catedral en la primera mitad del siglo XV.

La primera de estas encuadernaciones contiene el manuscrito Glossa ordinaria in genesim, realizada en la primera mitad del siglo XIII y se compone de una guarda de pergamino, 115 folios, una guarda de pergamino y otra media de pergamino duro, con unas dimensiones de 337 x 240 mm., caja de 270 x $140 \mathrm{~mm}$., de 23 líneas de texto y 47 en la glosa.

En el margen superior del folio I, en letras del siglo XIV aparece el precio: Genesis VI duplarum, y otra alusión al precio de compra, donde se indica que ha dado 18 sueltos y medio, aparece al verso de la guarda final: XVIII sol. et dimidium barch dedi.

La obra pertenece al Antiguo Fondo Toledano, donde se encuentra mencionado en el inventario del Liber Privilegiorum de la Catedral de Toledo de mediados del siglo XIII, con la siguiente descripción: Generis qui incipit: In principio creavit Deus celum et terram.

Las dimensiones de la encuadernación son 340 x 247 x $57 \mathrm{~mm}$. La signatura dentro de la biblioteca de la Catedral es BCT 3-6 aunque durante el siglo XVI tuvo la signatura 3-13 y durante el XVIII la 3-3.

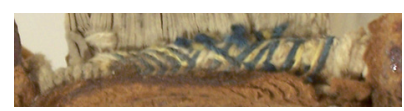

Fig. 1. Cabezada bicolor.

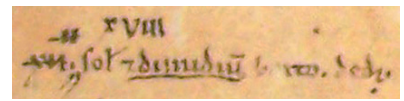

Fig. 2. Inscripción

manuscrita sobre el precio guarda posterior.

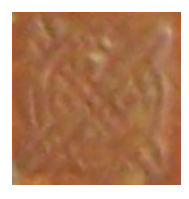

Fig. 3.

Círculo aspado.

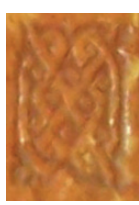

Fig. 4.

Rombo anudado.

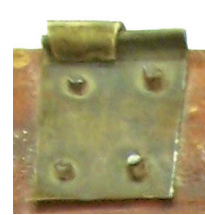

Fig. 5. Cierre cuadrangular de metal.

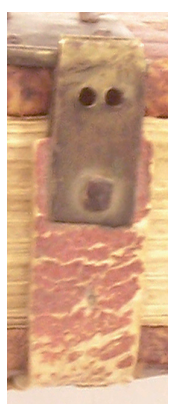

Fig. 6. Manecilla de piel y punta de metal. 
Las tapas son de madera recubiertas de piel de color avellana, al igual que el lomo, el cual está recubierto en los entrenervios por papel verjurado con inscripciones manuscritas; las guardas son de pergamino; el tejuelo de la tapa posterior es de pergamino con inscripciones manuscritas; los nervios son de tiras de piel curtida al alumbre ${ }^{4}$; el núcleo de las cabezadas es de tiras de piel curtida al alumbre, rodeadas de hilo de color blanco y recubiertas de hilos de colores azul y amarillo; los broches son de metal y las manecillas son de piel avellana y las puntas de metal; aparecen restos de metal pertenecientes a la cadena en la parte inferior de la tapa posterior; los cortes están pintados con tinta de color amarillo.

Las tapas están unidas al libro mediante tiras de piel curtida al alumbre, mediante un cosido con cuatro nervios hendidos a punto seguido; el lomo es recto; las cabezadas, realizadas manualmente, son simples y están unidas a las tapas y a los cuadernillos; el cuerpo del libro carece de cejas.

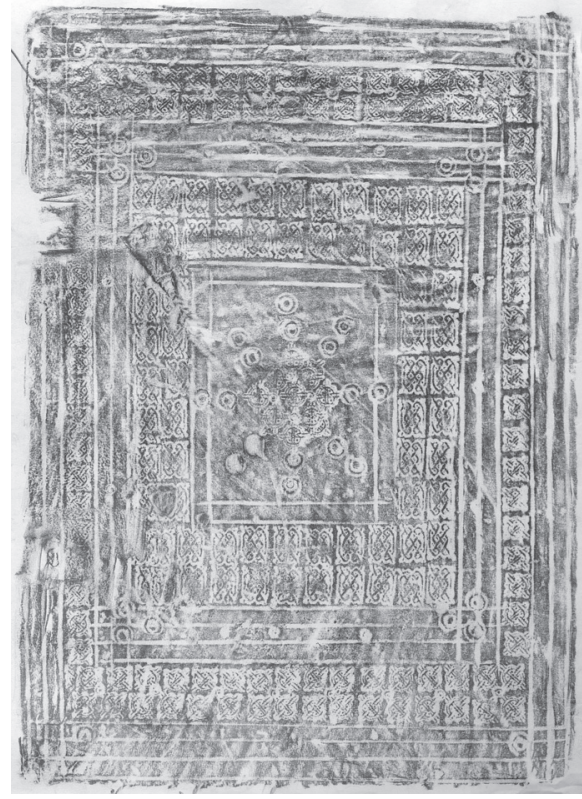

Fig. 7. Frotis tapa anterior.

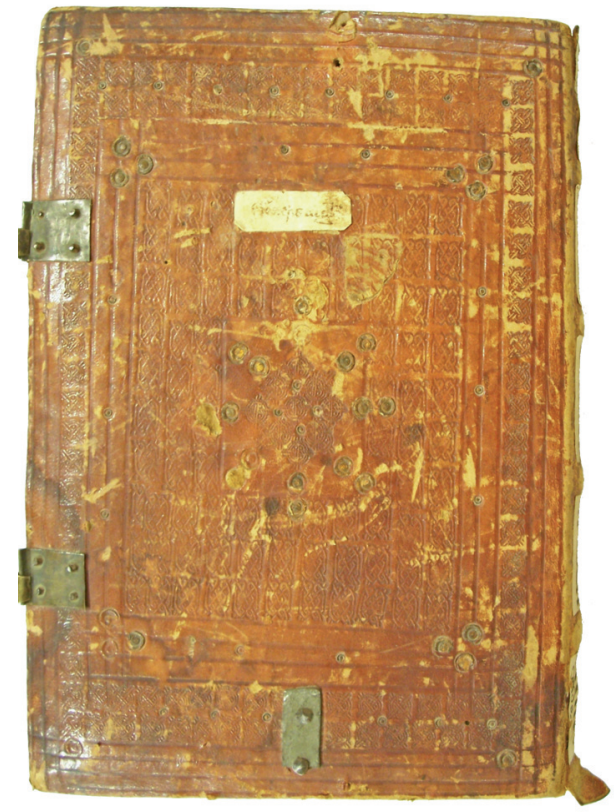

Fig. 8. Tapa posterior.

La estructura decorativa de las tapas es casi simétrica con pequeñas diferencias, y se compone de dos orlas rectangulares y un motivo central. La decoración se inicia con una orla formada por una hilera de círculos aspados cordiformes en las bandas verticales flanqueada por tres filetes paralelos a cada lado, y dos hileras en la parte superior e inferior de las tapas flanqueada por cuatro filetes paralelos a cada lado; la siguiente orla está formada por dos hileras de rombos encadenados y aspados en la tapa anterior, por tres hileras en la parte superior e inferior y por una hilera en

\footnotetext{
${ }^{4}$ Sulfato doble de aluminio y potasio que se emplea entre otros usos en encuadernación para el curtido de pieles.
} 
las bandas verticales de la tapa posterior. El centro de ambas tapas está ornamentado por una estrella de ocho puntas formada por círculos aspados cordiformes rodeados de filas de dos dobles circulillos puntados metálicos. En la tapa anterior este rombo está dentro de un rectángulo formado por dos hilos. Las entrecalles están decoradas con pequeños circulillos punteados metálicos y en las esquinas con tres dobles circulillos punteados también metálicos. En la tapa posterior aparece un pequeño tejuelo con la inscripción Glossa ordinaria in genesim. Los utensilios empleados han sido hierros sueltos y la técnica decorativa utilizada ha sido el gofrado ${ }^{5}$. Las cabezadas están decoradas con el alternado de hilos de colores azul y amarillo. Los cortes están pintados de color amarillo.

El estado de conservación es bueno, pero la encuadernación ha sido sometida a un uso indebido, por lo que la piel tiene algunos desgarros y mucho desgaste; en la tapa posterior aparecen agujeros de haber estado la encuadernación sujeta con cadena, junto a una lámina metálica en la parte inferior de la misma, sin duda con el mismo objeto; en la cabezada inferior hay pérdidas de hilo de seda.

La siguiente encuadernación contiene una copia manuscrita de la obra $\mathrm{Bi}$ blia beatae virginis Mariae de Alberto Magno (1206-1280) de finales del siglo XIV. La obra pertenece al Antiguo Fondo Toledano, donde ya se hallaba en 1455. Sus dimensiones son 263 x 184 x 475 mm. y su signatura es BCT 5-15.

Las tapas son de madera biselada recubiertas de piel de color marrón avellana, a igual que el lomo, el cual está recubierto de papel verjurado con inscripciones manuscritas; las guardas son de pergamino que cubren las dos contratapas y el lomo por su interior en una sola pieza; los nervios son de tiras de badana curtida al alumbre; el núcleo de las cabezadas es de tiras de badana rodeadas de hilo de color blanco; el broche es de metal y la manecilla es de tela bordada.

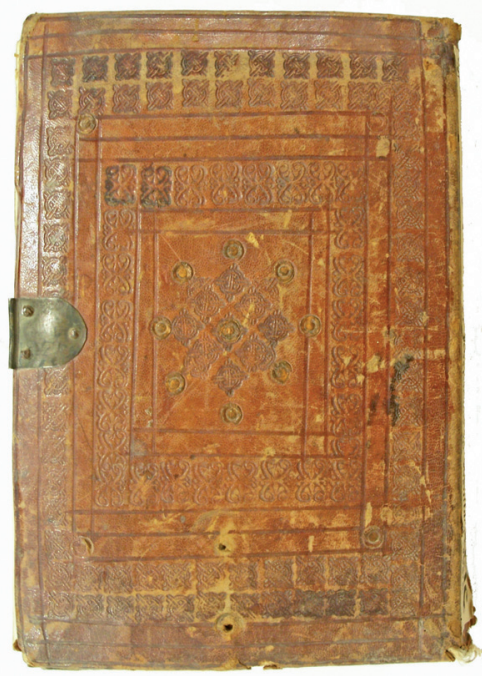

Fig. 9. Tapa posterior.

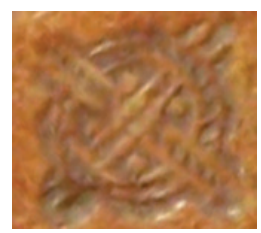

Fig. 10. Círculo aspado. Fig. 11. Palmeta doble.

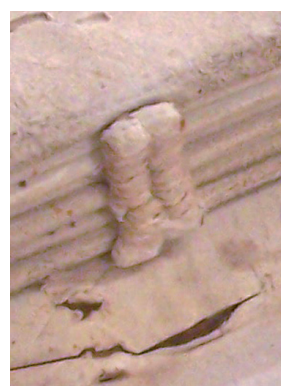

Fig. 12. Detalle de los nervios dobles.

5 Técnica de estampación de la piel, con calor y con humedad, que consisten en estampar un hierro o plancha por golpe o presión. También denominada estampación en seco. 
Las tapas están unidas al libro por tiras de badana curtida al alumbre; el cosido está realizado con tres nervios hendidos a punto seguido; el lomo es cuadrado y liso; las cabezadas, realizadas manualmente, son simples y están unidas a las tapas y a los cuadernillos; la encuadernación carece de cejas en los cortes.

La estructura de las tapas es simétrica y se compone de borduras rectangulares y una composición central realizada mediante la repetición de un círculo aspado. La decoración se inicia con un encuadramiento de tres filetes paralelos horizontales en la parte superior e inferior de las tapas, y dos verticales en cada una de las bandas, que se entrecruzan en las esquinas formando pequeños cuadrados, seguidos de una orla de círculos aspados cordiformes, con dos filas horizontales en la parte superior e inferior, y una vertical a cada banda de la tapa; a continuación aparecen de nuevo tres filetes paralelos horizontales en la parte superior e inferior, formando una entrecalle doble, y dos verticales a cada uno de los lados formando una entrecalle, seguida de la segunda orla, formada por la repetición de una palmeta doble. El centro de la tapa está decorado con la repetición de círculos aspados cordiformes, los cuales crean una composición de estrella de ocho puntas apareciendo alrededor ocho dobles circulillos metálicos con un tono cobrizo en pequeños círculos de piel. Las esquinas de la primera entrecalle están adornadas también con dobles circulillos metálicos con un tono cobrizo en pequeños círculos de piel. Los utensilios empleados han sido hierros sueltos y las técnicas decorativas utilizadas el gofrado. Los nervios no están ceñidos en el lomo. El tejuelo contiene la leyenda Biblia de Laudibus B. Marie et preparatio ad missam Ms. La manecilla es de tela bordada de color amarillo con una punta de metal. El broche de la tapa posterior tiene forma redondeada.

El estado de conservación es aceptable con agujeros en la parte inferior de ambas tapas, seguramente de una cadena, y la pérdida de la manecilla de piel inferior.

La siguiente encuadernación, similar a la anterior, contiene las obras manuscritas Comentarios sobre Job con las profecías y visiones de Roberto Usez, Dominicano en tiempo del Papa Nicolao IV de Pedro Blesense y Profecías y visiones en los tiempos del Papa Nicolao IV de Roberto de Usez (O.P.). Este volumen pertenece al Antiguo Fondo Toledano y aparece en el inventario de 1455; anteriormente es posible que fuera de Juan de Carvajal (n. ca 1399/1400 en Trujillo), ya que aparece su escudo en el folio 1, el cual fue canónigo de Astorga (1433), abad de Santa María de Husillos (1436), auditor del Tribunal de la Sagrada Rota, clérigo de la Cámara Apostólica, Legado papal en el Concilio de Basilea y la Dieta de Maguncia; obispo de Coria (1443, no tomó posesión), auditor general de la Cámara Apostólica (1445) y obispo de Plasencia (1446, la mantuvo hasta su muerte). Nombrado cardenal presbítero el 16 de diciembre de 1446 con el título de S. Angelo in Pescheria, y pasó a cardenal obispo de Porto y Santa Rufina el 26 de octubre de 1461 (manteniendo su título anterior in commendam hasta su muerte). Fue Legado de todos los papas, a los que sirvió en numerosas ocasiones como embajador y como administrador de la sede de Zamora (1467-1468). Murió en Roma el 6 de diciembre de 1469, enterrado en la iglesia de San Marcello con un epitafio redactado por el cardenal Bessarion. Fue conocido como infatigable e incorruptible y como el Cardenal de S. Angelo o de Plasencia. El escudo se describe así: en campo de oro, una banda de sable verde de arriba abajo y de izquierda a derecha; lleva el sombrero de un prelado eclesiástico, pero carece de borlas; lo sostienen dos leones rampantes sobre el fondo de una especie de cartel casi cuadrangular, que cuelga de un gancho, sobre el que apoya el ruiseñor. Debajo aparece una nota manuscrita cursiva del siglo XVI con la inscripción de la librería de la yglesia de Toledo. El texto manuscrito está realizado con letra gótica textual.

$\mathrm{Al}$ exterior de la primera cubierta aparece la forma de un poseedor, con letra cursiva del siglo XVI Hernando Pérez. Más arriba, casi ilegible el nombre de Diego López Ayala, el famoso canónigo obrero de la Catedral de Toledo de la primera mitad del siglo XVI. Sus dimensiones son 307 x 205 x 33 mm. y su signatura es BCT 6-26. 


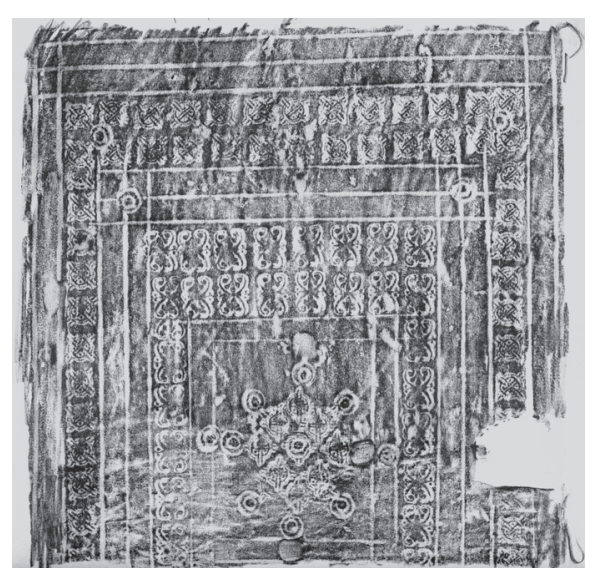

Fig. 13. Frotis - tapa anterior.

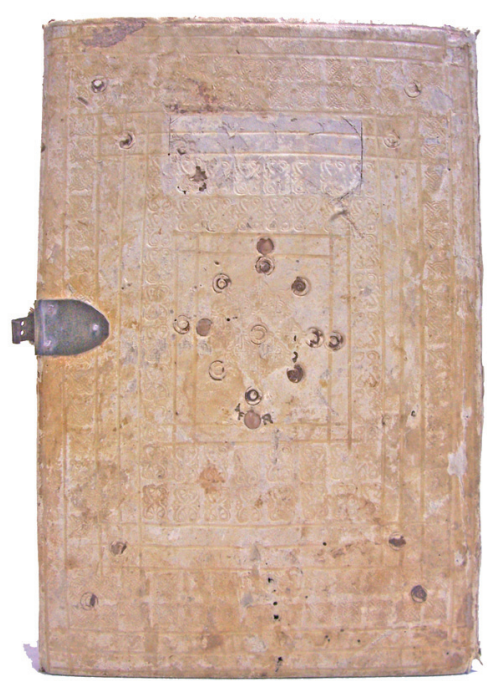

Fig. 14. Tapa posterior.

Las tapas son de madera recubiertas de piel curtida al alumbre, al igual que el lomo, que está recubierto de papel verjurado con inscripciones manuscritas; las guardas son de pergamino con inscripciones manuscritas en el anverso; el broche es de metal y las manecillas son de tela bordada y la punta de metal.

Las tapas están unidas al libro mediante tiras de piel curtida al alumbre; el cosido contiene cuatro nervios hendidos a punto seguido; el lomo es recto.

La estructura decorativa de las tapas es simétrica y está formada por una orla concéntrica exterior y un rectángulo central en cuyo interior aparece una estrella con motivos sueltos. La decoración se inicia con una bordura exterior formada por dos filetes seguidos de la primera orla formada por la repetición de un círculo aspado cordiforme, siendo en la parte superior e inferior la composición de dos hileras, y una en las bandas verticales. La entrecalle que sigue está formada por cuatro filetes que dan lugar a tres espacios vacíos o cintas tanto en la parte superior como inferior, y tres filetes en las bandas que dan lugar a dos cintas; en las esquinas aparecen dobles circulillos metálicos.

El rectángulo central está decorado con dos hileras de palmetas dobles en la banda superior e inferior y por una hilera en las bandas verticales. La composición central está formada por la repetición de círculos aspados cordiformes que forman una estrella de ocho puntas con dobles circulillos metálicos. Los utensilios empleados han sido hierros sueltos, florones, así como paletas con hilos y la técnica empleada ha sido el gofrado. El lomo está recubierto de papel verjurado con una inscripción manuscrita en tinta. El tejuelo contiene la leyenda Petrus blesensis in Job et Robertii de usecio prophetie. La manecilla es de tela bordada de color verde.

El estado de conservación no es el más adecuado, con agujeros en la parte superior e inferior de la tapa anterior y en la parte inferior de la tapa posterior posiblemente de una cadena; las tapas están muy deterioradas. 


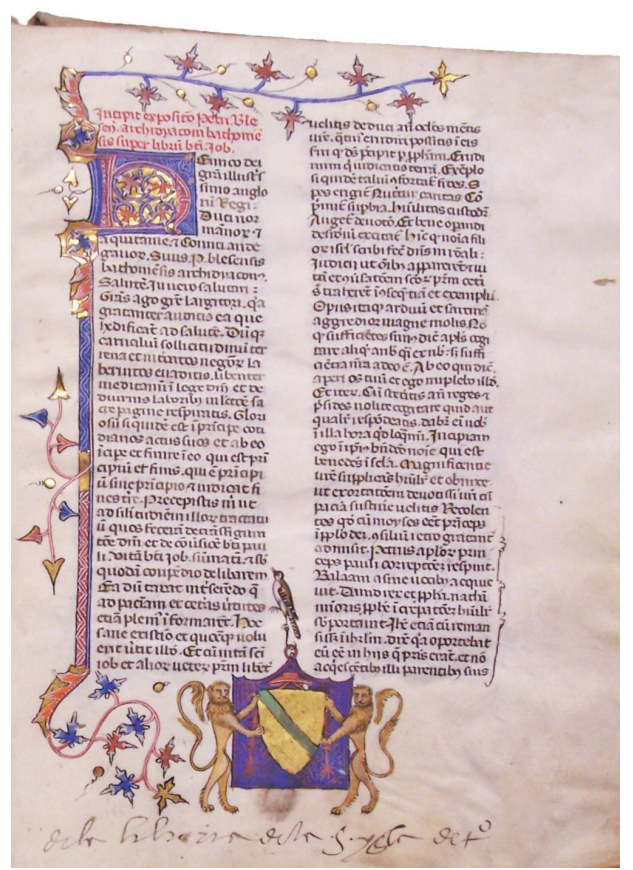

Fig. 15. Portada con escudo y capital miniada.

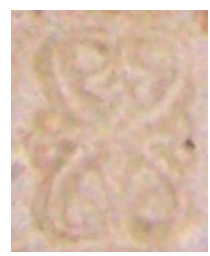

Fig. 16. Palmetas.

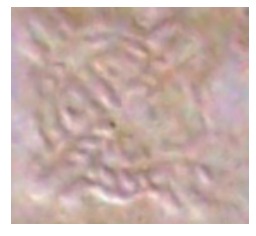

Fig. 17. Círculo aspado.

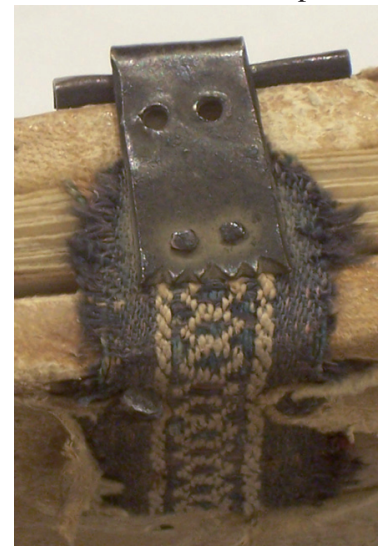

Fig. 18. Manecilla textil bordada y punta de metal.

La siguiente encuadernación con la misma estructura decorativa que los anteriores volúmenes, incluye los manuscritos Meditaciones y exortaciones del Santo Bernardo copia del siglo XIV y varias epístolas, cinco homilías y dieciséis sermones. copia del s. XIV.

La segunda obra es Arte oratoria, o Modo de predicar de Alain de Lille

La obra pertenece al Antiguo Fondo Toledano; primero fue de don Gil de Albornoz, arzobispo de Toledo (1338-1350), cardenal entre 1350 y 1356; después pasó a propiedad del arzobispo de Toledo don Pedro Tenorio (1377-1399), del cual aparece su escudo pintado en el último folio; por donación de éste pasó a la Biblioteca de la Catedral en 1383. En el folio 322 aparece pintado el escudo de don Pedro Tenorio (1377-1399). Sus dimensiones son 297 x 210 x $85 \mathrm{~mm}$. y su signatura es BCT 9-22. Muy posiblemente el escudo pintado de Pedro Tenorio se realizó cuando la obra formaba parte de su biblioteca, como signo de propiedad, y que una vez donado a la Catedral, se solicitó a un artesano externo la encuadernación de la obra siguiendo los mismos esquemas y los mismos motivos decorativos mudéjares de otras encuadernaciones de la época.

Pedro Tenorio nació en Talavera de la Reina (Toledo) ca. 1328 y muere el 18 de mayo de 1399 en Toledo. Pertenecía a una familia acomodada gallega con negocios en Talavera de la Reina. Tenorio inicia su trayectoria eclesiástica como arcediano en Toro (Zamora) y una canonjía en Zamora. Estuvo exiliado en Francia e Italia donde 
completó su formación. A su regreso a Castilla es capturado en la Batalle de Nájera y liberado siete años después. En 1371 es nombrado obispo y enviado a Coímbra (Portugal). El papa Gregorio XI le nombra arzobispo de Toledo, iniciando reformas en los tribunales eclesiásticos hasta llegar a formar parte del Consejo Real. Mandó construir el claustro bajo y la Capilla de San Blas dentro de la catedral de Toledo, así como los puentes de San Martín en Toledo y el puente que cruza el río Tajo en la localidad del Puente de Arzobispo (Toledo). Su escudo los podemos describir así: En campo de plata un león rampante de gules, linguado de gules y fajado con dos órdenes de jaqueles de azur y plata.

Las tapas son de madera recubiertas de piel de color marrón, al igual que el lomo; las guardas son de pergamino; los nervios son de tiras de piel curtida al alumbre; el núcleo de las cabezadas es de piel curtida al alumbre y recubierto de hilo de color blanco; el broche inferior es de metal, la manecilla es de piel marrón y la punta de metal; el entrenervio está recubierto de papel verjurado con inscripciones en tinta; la cartela de la tapa anterior es de papel verjurado.

Las tapas están unidas al libro mediante tiras de piel curtida al alumbre; el cosido se compone de cuatro nervios hendidos a punto seguido; el lomo está redondeado; las cabezadas, realizadas manualmente, están unidas a los cuadernillos y a las tapas; el corte delantero carece de ceja; el lomo no está adherido al cuerpo del libro lo que facilita la apertura de éste.

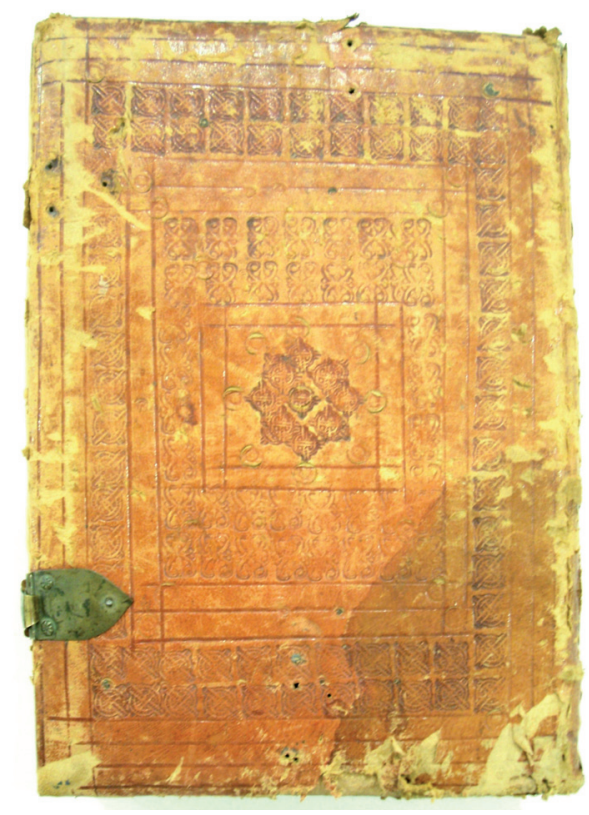

Fig. 19. Tapa posterior.

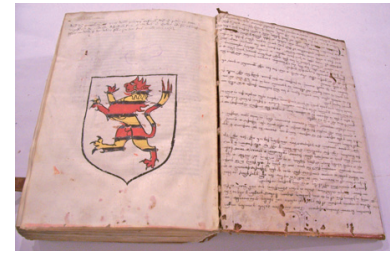

Fig. 19 bis. Escudo del arzobispo Pedro

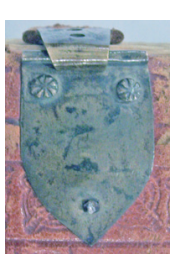

Fig. 20. Detalle del broche de metal.

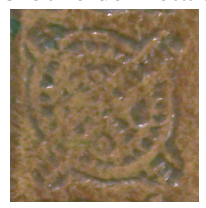

Fig. 22. Círculo aspado. Tenorio.

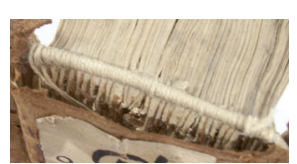

Fig. 21. Cabezada superior.

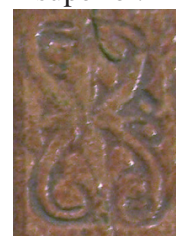

Fig. 23. Palmetas.

La estructura decorativa de las tapas no es simétrica y está formado por una orla concéntrica exterior y un rectángulo central en cuyo interior aparece una composición de hierros sueltos. La decoración se inicia con una bordura 
exterior formada por cuatro filetes simples en la parte superior e inferior y tres filetes simples en las bandas verticales, que dan lugar a espacios en las bandas; a continuación aparece la primera orla formada por la repetición de un círculo aspado cordiforme, siendo en la parte superior e inferior la composición de dos hileras, y una en las bandas verticales. La entrecalle siguiente está formada por tres filetes que dan lugar a dos espacios vacíos tanto en la parte superior como inferior, y dos filetes en las bandas verticales que dan lugar a una entrecalle; en las esquinas aparece un doble circulillo, posiblemente estampado. El rectángulo central está formado por la repetición de hierro con dos palmetas, dos hileras en la parte superior e inferior y una hilera en las bandas verticales. La composición central está formada por la repetición de nueve círculos aspados cordiformes que forman una estrella de ocho puntas, junto a pequeños circulillos o botones en las puntas, posiblemente estampados. En la tapa anterior aparecen restos de una cartela de papel verjurado con inscripciones góticas. Los utensilios empleados han sido hierros sueltos y la técnica decorativa utilizada ha sido el gofrado. La guarda anterior está completamente recubierta de inscripciones manuscritas. El broche inferior es de metal y finaliza en punta. Los entrenervios están recubiertos de papel verjurado con inscripciones góticas en tinta, y los nervios están decorados con una paleta de un hilo. El tejuelo contiene la leyenda D. Bernardi opera et Alanus de arte predicandi $M s$.

La siguiente encuadernación, que recubre el manuscrito titulado Tractatus de incarnatione Domini, con letra gótica textual, pertenece al Antiguo Fondo Toledano, su signatura es BCT 17-15 y sus dimensiones son 215 x 157 x 45 mm.

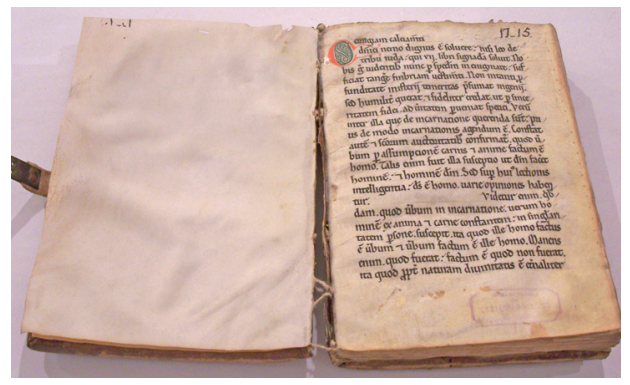

Fig. 24. Primer folio manuscrito iluminado.

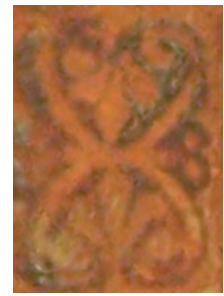

Fig. 25. Palmeta doble.

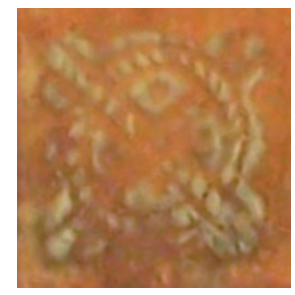

Fig. 26. Círculo aspado cordiforme.

Las tapas son de madera recubiertas de piel de color marrón, al igual que el lomo; las guardas de pergamino; los nervios son de tiras de piel curtida al alumbre; las cabezadas son de tiras de piel curtida al alumbre rodeadas de hilo blanco; el broche es de metal, la manecilla es de badana al alumbre y la punta de metal; el lomo está recubierto de papel verjurado blanco con inscripciones en tinta. 


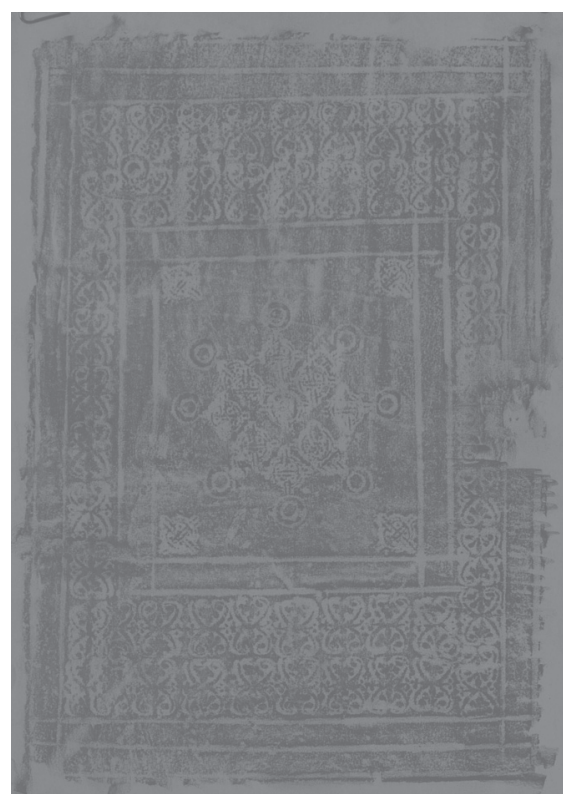

Fig. 27. Frotis tapa anterior.

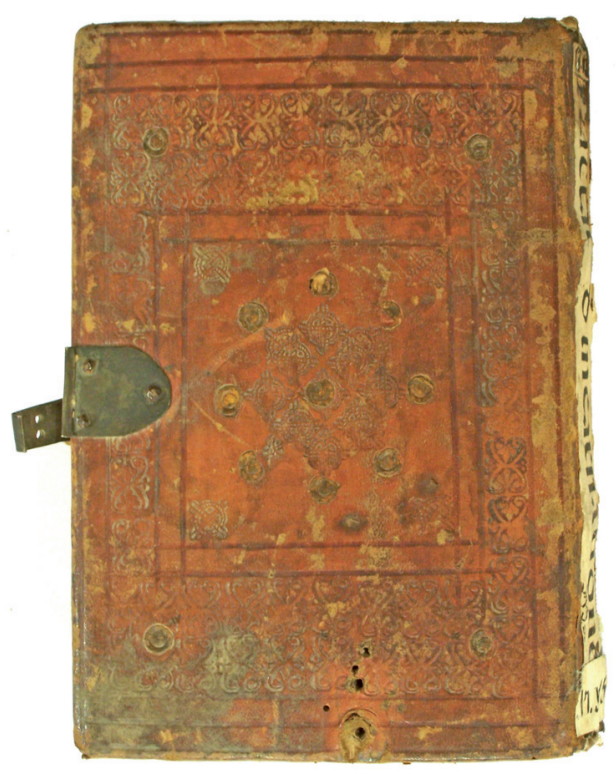

Fig. 28. Tapa posterior.

Las tapas están unidas al libro mediante tiras de piel curtida al alumbre; el cosido contiene dos nervios hendidos a punto seguido; el lomo es recto; las cabezadas están unidas a los cuadernillos y a las tapas; los cortes carecen de cejas.

La estructura decorativa de las tapas es simétrica y se compone de una orla y una composición central. La decoración se inicia con una bordura formada por tres filetes que dan lugar a dos espacios vacíos de decoración en la parte superior e inferior de las tapas, y en las bandas verticales por dos filetes que dan lugar a un espacio vacío de decoración; la orla está formada por la repetición, en dos hileras, de una palmeta doble en la parte superior e inferior de la tapa, y una hilera en las bandas; en las esquinas de la orla, y rodeando la composición central, aparecen pequeños circulillos o botones de piel adheridos metálicos estampados. En la parte central, y encuadrada por dos filetes, aparece una composición formada por la repetición de círculos aspados cordiformes que dan lugar a una estrella de ocho puntas. Los utensilios empleados han sido hierros sueltos mudéjares y paletas de un hilo y la técnica decorativa empleada ha sido el gofrado. El broche de la tapa posterior tiene un acabado circular. El lomo está recubierto de papel verjurado con inscripciones góticas con el título de la obra. Las cabezadas carecen de hilos de colores.

El estado de conservación es bueno aunque aparecen unas roturas de la piel y de las tiras de piel de los nervios de la tapa anterior; también aparecen agujeros, posiblemente restos de una cadena, en la parte inferior de la tapa posterior.

La siguiente encuadernación contiene la obra de Justiniano I, conocido como el Emperador de Oriente, Digestum Novum, con la glosa ordinaria de Accursio al margen. Este manuscrito fue realizado entre el siglo XIII y XIV, en pergamino con unas dimensiones de 410 × 265, aunque el texto es de dimensiones variables, con 310 folios a 2 columnas. En las dos guardas últimas hay fragmentos de la Compilatio I 
Antiqua. I Comp. 3.20.2 fragmentario hasta 3.23.5 y 3.26.6 fragmentario hasta 3.26.9 también fragmentario. Es de principios del S. XIII.

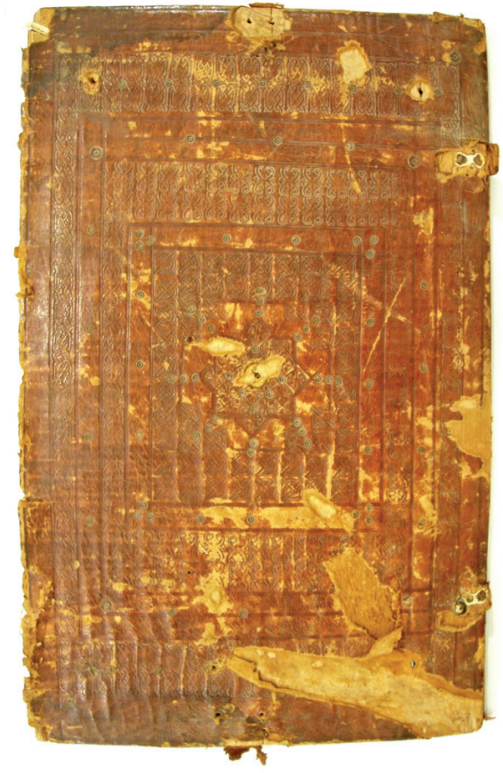

Fig. 29. Tapa posterior.

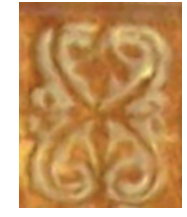

Fig. 30. Palmetas dobles.

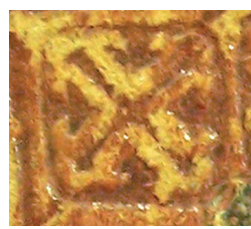

Fig. 32. Cruceta.

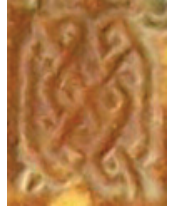

Fig. 31. Rombo anudado.

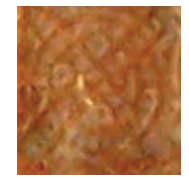

Fig. 33. Círculo aspado.

Sus dimensiones son 427 x 280 X 110 mm., pertenece al Antiguo Fondo Toledano y su signatura es BCT 32-5.

Las tapas son de madera recubiertas de piel de color avellana, al igual que el lomo, que está recubierto de papel verjurado con inscripciones en tinta; las guardas son de pergamino con inscripciones manuscritas en tinta; los refuerzos de los entrenervios del lomo son de pergamino; los nervios son de tiras de piel curtida al alumbre; el núcleo de las cabezadas es de tiras de piel curtida al alumbre y pequeños cordoncillos rodeados de hilo blanco recubiertos, a continuación, con hilos de seda de colores verde y amarillo; los broches son de metal y las manecillas son de piel color avellana.

Las tapas están unidas al libro mediante tiras de piel curtida al alumbre; el cosido contiene cinco nervios hendidos a punto seguido; el lomo está redondeado; las cabezadas, realizadas manualmente, están unidas a las tapas y a los cuadernillos; el corte delantero carece de ceja.

La estructura decorativa de las tapas es simétrica y se compone de tres orlas concéntricas y una estrella central de ocho puntas. La decoración se inicia con un doble fileteado en la parte superior e inferior, seguida de una primera orla formada por dos hileras horizontales de rombos anudados, en la parte superior e inferior, y una hilera en las bandas verticales, flanqueadas por dos filetes a cada lado; la segunda orla está decorada con dos hileras de palmetas dobles estilizadas, en la parte superior e inferior, y una hilera en las bandas verticales, flanqueada por dos filetes a cada lado. El rectángulo central está ornamentado con círculos aspados, dejando el centro para la estampación de una estrella de ocho puntas relleno de pequeñas crucetas, con pequeños circulillos metálicos en su interior y en los vértices de la estrella. Las entrecalles 
están decoradas con diversos circulillos dorados en el centro y en las esquinas. Los utensilios empleados han sido hierros sueltos y la técnica decorativa el gofrado. En el lomo aparece un gran tejuelo con la inscripción manuscrita Digestum Novum.

El estado de conservación no es el más adecuado apareciendo la encuadernación muy deteriorada. La tapa anterior aparece desprendida del cuerpo del libro; la piel de la parte inferior del lomo también está desprendida; hay pérdida de bollones en las esquinas y centro de ambas tapas, y pérdida de cierres metálicos en la parte superior e inferior de las tapas.

\section{ENCUADERNACIONES CON FLORES DE LIS Y CÍRCULOS ASPADOS}

Las siguientes cinco encuadernaciones toledanas contienen una estructura decorativa donde se puede observar el empleo de los mismos motivos decorativos como flores de lis, círculos aspados cordiformes, lazos simples redondeados cordiformes, rombos anudados y fajas de bandas cóncavas, y al igual que el grupo anterior decoradas con palmetas y círculos aspados, muy posiblemente fueron realizadas en la primera mitad del siglo XV en un mismo taller toledano o talleres de la misma época donde se empleaban los mismos esquemas y motivos decorativos.

La primera encuadernación contiene el II volumen de la obra manuscrita Postilla sobre toda la Biblia de Nicolaus Lyra del siglo XIV. La obra pertenece al Antiguo Fondo Toledano, sus dimensiones son 483 x 328 x 120 mm. y su signatura es BCT 7-16.

Las tapas son de madera recubierta de piel de color marrón, al igual que el lomo que está recubierto por papel verjurado con inscripciones góticas en tinta; las guardas son de pergamino; los nervios son de tiras de piel curtida al alumbre; los broches son de metal y las manecillas son de piel; aparecen cinco bollones, cuatro en las esquinas y uno en el centro.

Las tapas están unidas al libro mediante tiras de piel curtida al alumbre; el cosido contiene diez nervios hendidos a punto seguido; el lomo está redondeado.

La estructura decorativa de las tapas es simétrica y está formada por dos orlas y un rectángulo central con una estrella de ocho puntas. La decoración se inicia con tres encuadramientos verticales de dos hilos cada una, y cuatro horizontales en la parte superior e inferior de la tapa; a continuación aparece una orla formada por la repetición de un círculo aspado cordiforme y flanqueada de dos hilos a los lados en las bandas verticales y el mismo motivo se repite en dos hileras horizontales en la parte superior e inferior de las tapas; seguidamente aparecen dos entrecalles verticales en los lados de la tapa y tres horizontales en la parte superior e inferior de la tapa realizada con dos hilos, y decoradas en las esquinas por tres dobles circulillos punteados o botones, posiblemente estampados. La siguiente orla está formada por pequeñas flores de lis, que se repiten con dos hileras en la parte superior e inferior y una hilera en las bandas verticales. Siguiendo hacia el interior aparece una entrecalle libre de decoración, y dos entrecalles en la parte superior e inferior del encuadramiento, sólo decoradas en las esquinas por un doble circulillo punteado, posiblemente metálicos. El último encuadramiento está formado por la repetición vertical de un pequeño hierro con un lazo simple cordiforme y un punto en el centro, con dos hileras horizontales en la banda superior e inferior y una hilera en las bandas verticales. El motivo central está formado por una estrella de ocho puntas realizada por un encuadramiento doble de dos hilos; el interior de la estrella está decorado con círculos aspados cordiformes; las puntas de la estrella central están decoradas por cuatro dobles circulillos puntados estampados en forma oblicua. En el centro y en las esquinas aparecen cinco bullones lisos sin decoración. Los utensilios empleados han sido paletas y florones y las técnicas 
decorativas empleadas han sido el estezado y el gofrado. El lomo está recubierto por papel verjurado con la inscripción en tinta Nicolai Lirani postilla pars $2^{a}$ continens a libris Salomonis Ms. Los broches son diferentes, el superior tiene forma de hoja de trébol, con la hoja intermedia más grande; el segundo broche tiene forma semicircular, con tres pequeños círculos unidos como si fuera una pequeña hoja de trébol. La encuadernación carece de decoración en los cortes y las guardas y de cabezadas.

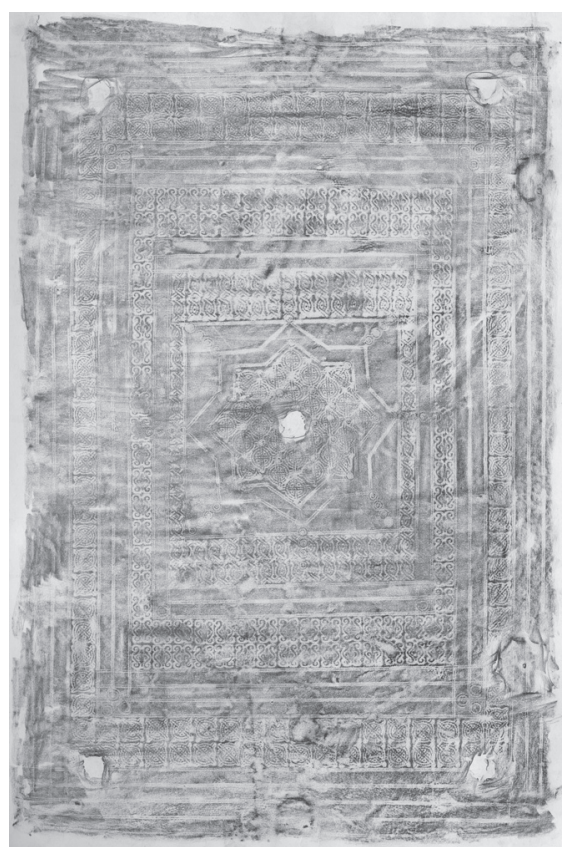

Fig. 34. Frotis.

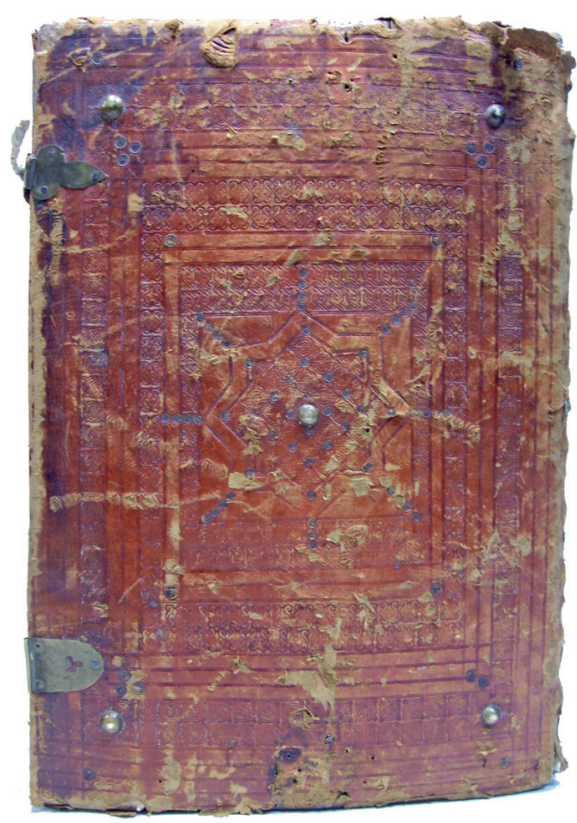

Fig. 35. Tapa posterior.

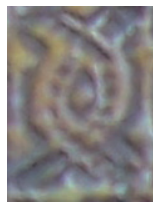

Fig. 37. Lazo simple redondeado cordiforme.

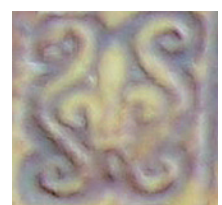

Fig. 38. Flor de lis.

Fig. 36. Círculo aspado cordiforme.

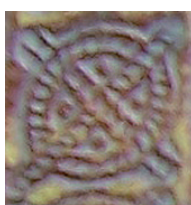

El estado de conservación del cuerpo del libro de este segundo volumen es bueno, pero la encuadernación está bastante deteriorada, con la lomera en parte desprendida, el cuero rajado apreciándose el alma de la encuadernación; también aparecen restos de agujeros donde estaban las cadenas.

La siguiente encuadernación contiene el Libro copiador de escrituras de donación, trueques, arrendamiento y fianzas de propiedades inmuebles otorgadas por el Cabildo de la Catedral de Toledo tanto dentro como fuera de la ciudad de Toledo 
del siglo XIII. Las dimensiones de la encuadernación son 474 x 330 x 52 mm., pertenece al Antiguo Fondo Toledano y su signatura es BCT 42-40.

Las tapas son de madera recubiertas de piel de color marrón, al igual que el lomo; las guardas son de pergamino; los nervios son de tiras de badana curtida al alumbre; los refuerzos del lomo son de tela; aparecen restos de los broches de piel marrón; los bullones de las esquinas de las tapas y dos broches del centro de la tapa posterior son de metal; las cabezadas, con núcleo de piel curtida al alumbre, están rodeadas de hilo blanco.

Las tapas están unidas al libro mediante tres nervios hendidos de tiras de badana curtida al alumbre y con un cosido a punto seguido; el lomo está redondeado; la encuadernación carece de cejas.

La estructura de las tapas es simétrica y se compone de una orla concéntrica exterior, un rectángulo central y un círculo central que parece imitar a un sol con rayos dorados. La decoración se inicia con dos grupos de dos filetes que se entrecruzan en las esquinas ornamentadas por dobles circulillos metálicos. La primera orla está formada por dos hileras, en las bandas horizontales y por una hilera en las bandas verticales, de círculos aspados cordiformes, junto a botones dorados en los vértices de las uniones entre los hierros; la siguiente orla está ornamentada por tres hileras en las bandas horizontales y por dos hileras en las bandas verticales, de flores de lis estilizadas, como único motivo gótico. La entrecalle entre la primera y segunda orla está ornamentada por dos grupos de dos filetes paralelos cada uno, que al cruzarse en las esquinas forman cuatro pequeños cuadrados. El rectángulo central está decorado con una composición de círculos aspados cordiformes que forma una estrella y ocho composiciones que imitan rayos de sol, realizados con dobles circulillos metálicos. Los utensilios empleados han sido hierros sueltos y la técnica decorativas utilizada ha sido el gofrado.

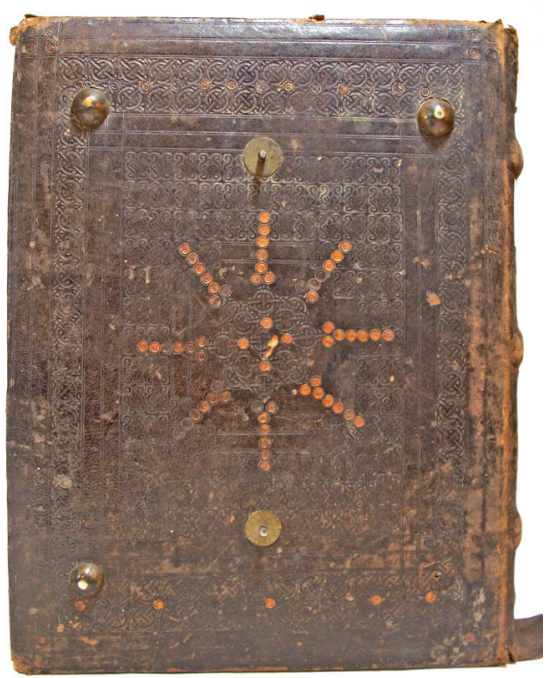

Fig. 39. Tapa posterior.

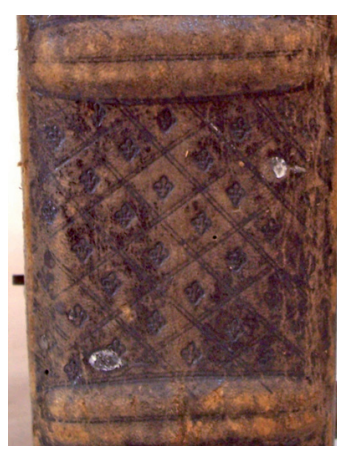

Fig. 40. Decoración del entrenervio con pequeñas flores de lis.

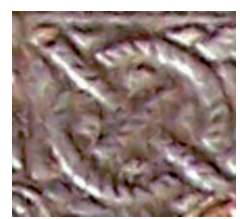

Fig. 41. Círculo aspado cordiforme.

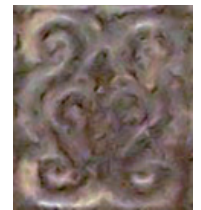

Fig. 42. Flor de lis. 
El lomo está decorado con filetes dobles gofrados que se entrecruzan formando pequeños rombos, en cuyo interior se estampa una pequeña flor de lis también gofrada. Los nervios están decorados con dobles filetes paralelos gofrados, lo que acentúa el empleo de nervios hendidos.

El estado de conservación es aceptable con pérdida de las manecillas de piel en la tapa posterior y de varios bollones en ambas tapas; también aparece con una rotura el núcleo de la cabezada inferior.

Este volumen contiene la obra Speculum Iudiciale de Guillermo Durante, aunque no tenemos noticia del copista, fue realizada entre 1271 y 1276 , y revisada en 1289; es un completo manual de conocimientos teóricos y prácticos de Derecho civil y canónico sobre materias procesales; en el siglo XIV recibió Additiones de Juan de Andrés y de Baldo. Se conservan numerosos manuscritos y ediciones, contabilizándose medio centenar de ejemplares hasta finales del siglo XVII. Se le cita en numerosas ocasiones en la tradición manuscrita medieval y en las obras de casi todos los canonistas hasta el Código de 1918.

La obra que describimos tiene como soporte el pergamino de $260+78 \mathrm{ff}$. a 2 columnas con $86\left(1^{\mathrm{a}}\right)$ y $80\left(2^{\mathrm{a}}\right)$; el tamaño de los folios es de 455 x $290 \mathrm{~mm}$. y el del texto 330 x $195 \mathrm{~mm}$. La obra pertenece al Antiguo Fondo Toledano, sus dimensiones son 475 x 300 x 115 mm., su signatura es BCT 24-4 (signatura antigua: 20-11) y perteneció a la biblioteca del Arzobispo don Pedro Tenorio (1376-1399).

Las tapas son de madera recubiertas de piel de color marrón, al igual que el lomo, que además está recubierto con papel verjurado con inscripciones manuscritas en los entrenervios; las guardas son de pergamino con un escudo pintado en el verso de la guarda volante de la tapa anterior; los nervios son de tiras de piel curtida al alumbre; el núcleo de la cabezada superior es de tira de piel curtida al alumbre y pequeños cordoncillos rodeados de hilo de color blanco y todo recubierto de hilos de seda de colores rojo y amarillo; los broches son de metal y los restos de las manecillas son de piel marrón, dos en el corte delantero, uno en el corte de superior y otro en el inferior; también aparecen pequeños bollones en las esquinas y en el centro de ambas tapas.

Las tapas están unidas al libro mediante tiras de piel curtida al alumbre, el cosido contiene siete nervios hendidos a punto seguido; el lomo está redondeado; las cabezadas son simples, están realizadas manualmente, y unidas a las tapas y a los cuadernillos.

La estructura decorativa de las tapas es simétrica y se compone de dos orlas concéntricas, un rectángulo central, dentro del cual aparece una estrella de ocho puntas. La decoración se inicia con una bordura exterior de cuatro dobles filetes paralelos horizontales, en la parte superior e inferior de las tapas, y dos dobles filetes verticales, en las bandas laterales, seguida de una primera orla formada por dos hileras horizontales de círculos aspados en la parte superior e inferior, y una hilera vertical en las bandas, flanqueadas por dos filetes a cada lado; la siguiente orla está formada dos hileras horizontales de flores de lis estilizadas en la parte superior e inferior, y una hilera vertical en las bandas, y flanqueadas por dos filetes a cada lado; las entrecalles están decoradas por dobles circulillos metálicos en las esquinas. El rectángulo central está decorado con dos fajas punteadas que dividen parejas de aspas cóncavas, también punteadas; el centro de este rectángulo está decorado por una estrella de ocho puntas formada por círculos aspados, con dobles circulillos metálicos en sus vértices; la estrella está formada por un doble fileteado paralelo. Los utensilios empleados han sido hierros sueltos y las técnicas decorativas han sido el gofrado y el dorado en los dobles circulillos. Los nervios están decorados con un doble filete horizontal, que acentúa el empleo de nervios hendidos. Los entrenervios están decorados con dobles filetes, que al entrecruzarse forman pequeños rombos con pequeñas flores de lis en su interior; los entrenervios están recubiertos de un tejuelo con la inscripción manuscrita Speculum 
Guillelmi Durandi. En la guarda anterior aparece pintado el escudo del arzobispo Pedro Tenorio. Las cabezadas están decoradas con el alternado de hilos de seda de colores amarillo y rojo. Los broches están decorados con tres agujeros que imitan un trébol. En las esquinas y en el centro de las tapas aparecen pequeños bollones metálicos, con pérdida de varios de ellos.

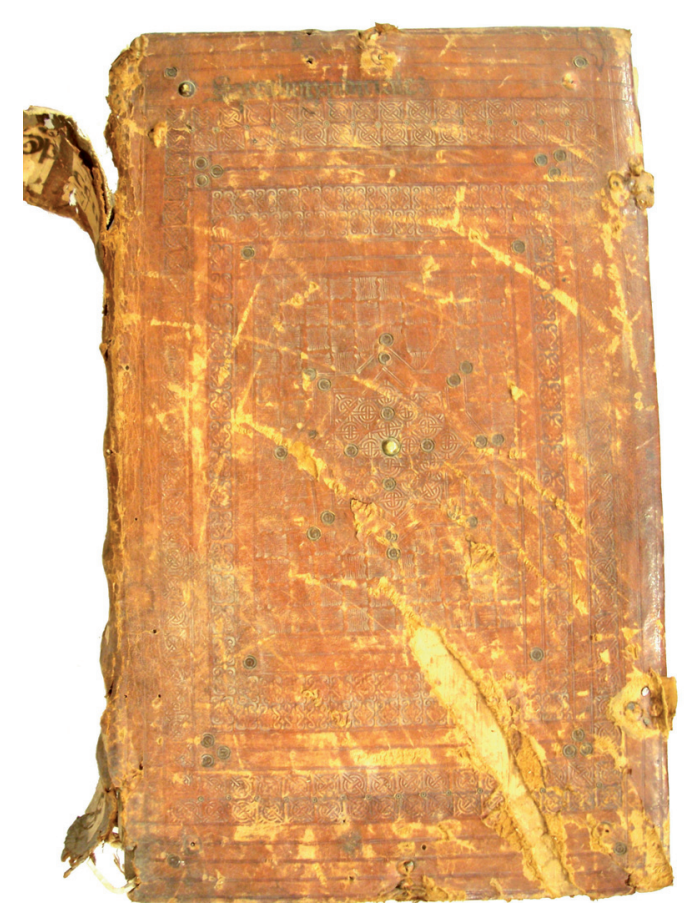

Fig. 43. Tapa anterior.

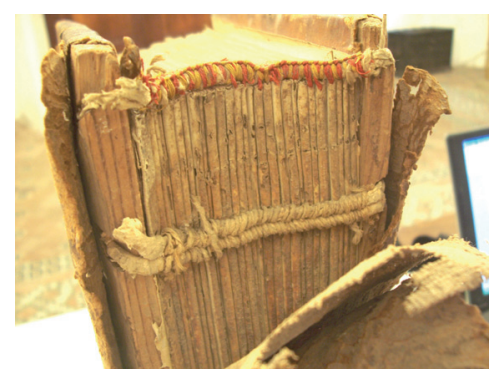

Fig. 44. Cabezada bicolor y de los nervios dobles.

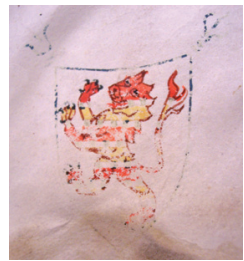

Fig. 45. Escudo pintado del arzobispo Pedro Tenorio.

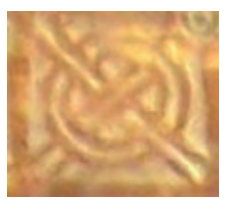

Fig. 47. Círculo aspado.

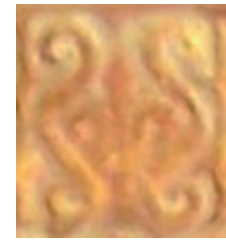

Fig. 46. Flor de lis.

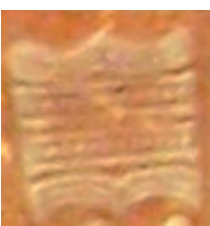

Fig. 48. Motivos curvos y rectos.

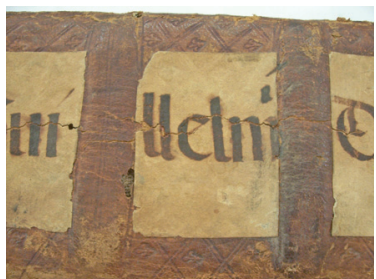

Fig. 49. Detalle de la decoración del lomo. 
El estado de conservación no es el más adecuado con numerosas rozaduras, roturas de la piel en las tapas y en el lomo que dejan al descubierto el cosido, los nervios y donde se aprecia la pérdida de la cabezada inferior.

La siguiente encuadernación contiene una Biblia Sacra latina manuscrita realizada seguramente en el siglo XIII; forma parte del Antiguo Fondo Toledano, las dimensiones de la encuadernación son 380 x 250 x $110 \mathrm{~mm}$. y su signatura es BCT 2-5.

Las tapas son de madera recubiertas de piel de color marrón avellana, al igual que el lomo; las guardas son de pergamino; los nervios son de tiras de piel curtida al alumbre; el núcleo de las cabezadas es de piel curtida al alumbre, rodeado de hilo blanco y recubierto de hilos de seda de colores rojo y amarillo; los broches de las tapas son de tiras de piel y metal; la cartela de la tapa delantera es de pergamino; los entrenervios están recubiertos de papel verjurado con inscripciones en tinta.

Las tapas están unidas al libro mediante tiras de piel curtida al alumbre y con un cosido de cinco nervios hendidos a punto seguido; el lomo es recto; las cabezadas, realizadas manualmente, están unidas a los cuadernillos y a las tapas; el corte delantero carece de ceja.

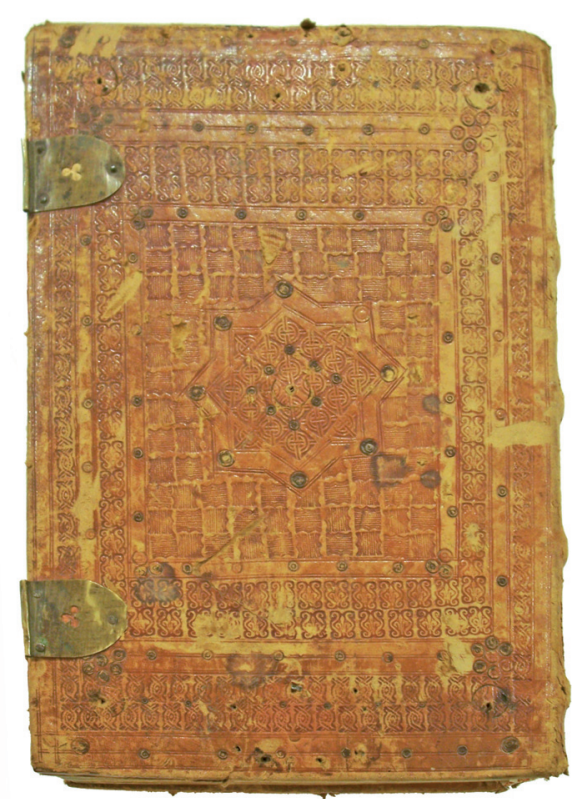

Fig. 49 bis 1. Tapa posterior.

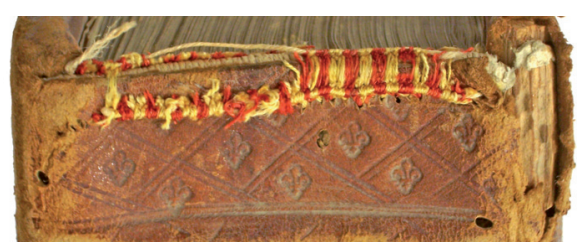

Fig. 49 bis 2. Cabezada bicolor y pequeñas flores de lis.

Fig. 49 bis 3. Manecilla de piel y broche de metal.

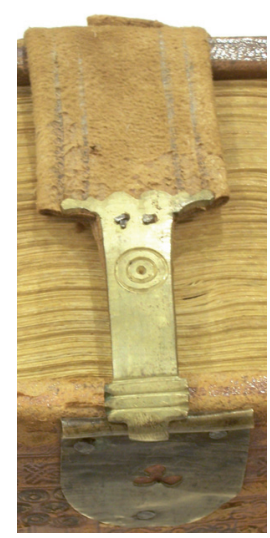

La estructura decorativa de las tapas es simétrica y se compone de diversas orlas concéntricas y una estrella de ocho puntas en el centro de ambas tapas. La decoración se inicia con un encuadramiento de cuatro filetes en las bandas, dos a cada lado, y seis filetes en la parte superior e inferior, que dan lugar a dos espacios, formados con dos filetes a cada lado. Sobre los filetes de la parte superior e inferior 
se estampan seis pequeños circulillos punteados o botones de piel y dos más grandes en las esquinas, posiblemente coloreados o metálicos. La primera orla está formada por la repetición de un lazo simple redondeado, con dos filas en la parte inferior y superior, y una en las bandas; a continuación aparece una entrecalle formada por cuatro filetes en las bandas, dos a cada lado, y seis filetes en la parte superior e inferior, que dan lugar a dos espacios donde se estampan pequeños circulillos punteados o botones de piel, similares a los del encuadramiento exterior y en las esquinas aparece una composición de siete circulillos o botones que dan lugar a una flor. En la siguiente orla o encuadramiento aparece la repetición de un motivo con una flor de lis en su interior, con dos filas en la parte inferior y superior, y una en las bandas; seguidamente se forma una entrecalle formada por cuatro filetes en cuyo interior aparecen pequeños circulillos punteados o botones de piel, posiblemente coloreados o metálicos, distribuidos por toda la entrecalle. El rectángulo central está decorado con la repetición de un motivo formado por dos fajas que dividen parejas de aspas cóncavas, todo ello cordiforme; además en el centro del rectángulo aparece una estrella formada por una cinta realizada por cuatro filetes y que en cada esquina o punta aparece un circulillo punteado de piel, posiblemente coloreado o metálico; el interior de la estrella se repite un círculo aspado, y que en el centro, alrededor del bollón central formando un rombo, aparecen ocho circulillos punteados de piel, posiblemente coloreados o metálicos. La decoración de las tapas finaliza con los dos broches metálicos en la tapa posterior donde aparece una imitación de tres hojas de trébol; y dos tiras de piel y broches de metal decorados con dos circulillos y un punto central en tapa anterior. Los utensilios empleados han sido florones mudéjares y paletas de dos hilos, y la técnica empleada ha sido el gofrado. Los entrenervios están decorados mediante una estructura de paletas de dos hilos que se entrecruzan formando una composición de rombos en cuyo interior aparece una pequeña flor de lis; los nervios están decorados con una paleta de dos hilos, todo ello gofrado; los entrenervios están recubiertos de papel verjurado con inscripciones en letra gótica con el título del libro. Las cabezadas están decoradas con el alternado de hilos seda de colores rojo y amarillo. En la primera guarda aparece una tabla del orden de los libros.

El estado de conservación es aceptable con agujeros de bollones en las esquinas y en el centro de las tapas, pérdida de la piel en las esquinas y parte superior en la tapa anterior y el deterioro de las cabezadas con pérdida de los hilos de colores.

La cuarta encuadernación contiene la obra de Justiniano I, Emperador de Oriente, titulada Código Justiniano, una copia manuscrita del siglo XIV. En el folio 6 aparece el escudo de Tenorio (1376-1399). Los folios miden 445 x $270 \mathrm{~mm}$., siendo su espesor entre 150 y 180 micras. La obra contiene 330 folios, de los cuales 332 corresponden al cuerpo del libro. En la actualidad aparece paginado a lápiz en el borde inferior, quedando algún resto de la paginación antigua en la parte superior derecha. Se estructura en 65 cuadernillos, generalmente en forma de cuaterniones. La altura de la caja es variable, dependiendo de los textos del código y de los comentarios que le acompañan alrededor, oscilando entre 220 a $395 \mathrm{~mm}$.; la anchura es más constante estando entre 200 a $230 \mathrm{~mm}$. 


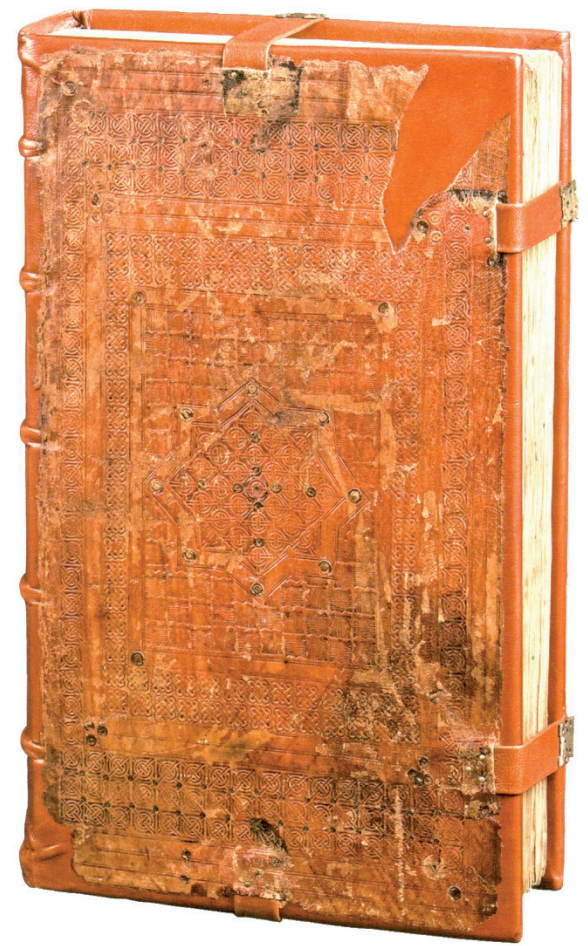

Fig. 50. Tapa anterior.

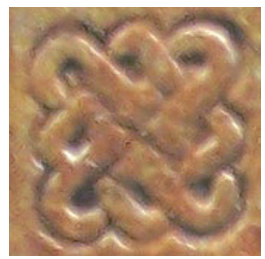

Fig. 51. Rombo anudado.

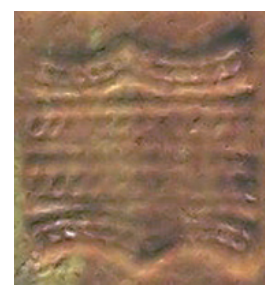

Fig. 52. Motivos curvos y rectos cordiformes.

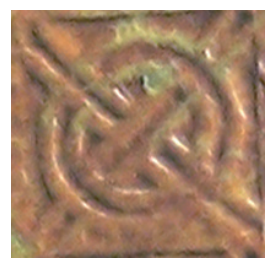

Fig. 53. Círculo aspado no cordiforme.

Las dimensiones son 460 × 285 x 98 mm., pertenece al Antiguo Fondo Toledano y su signatura es BCT $32-15^{6}$.

Las tapas son de madera recubiertas de piel de color marrón, al igual que el lomo; las guardas son de pergamino; los nervios son de tiras de badana curtida al alumbre y el hilo es de lino blanco; el núcleo de las cabezadas es de badana curtida al alumbre rodeado de hilo de fibra vegetal; los broches son nuevos de metal, las manecillas son de tiras de piel marrón y las puntas de metal.

Las tapas están unidas al libro mediante cinco nervios hendidos con tiras de badana al alumbre y con un cosido a punto seguido; el lomo está redondeado; las cabezadas están unidas a los cuadernillos y a las tapas.

La estructura de las tapas es simétrica y se compone de dos orlas rectangulares y una estrella de ocho puntas en el centro. La decoración se inicia con tres borduras de dos filetes cada una en las bandas horizontales y dos borduras similares en las bandas verticales. La primera orla está formada por tres hileras de círculos aspados en las bandas horizontales, y una hilera, similar a la anterior, de círculos aspados en las bandas

\footnotetext{
${ }^{6}$ Esta encuadernación formó parte de la exposición Las encuadernaciones artísticas de la Catedral de Toledo, celebrada en la Capilla de Reyes Nuevos de la Catedral entre el 10 de junio al 30 de septiembre de 2009.
} 
verticales, con pequeños punzones o circulillos pintados en los vértices de las aspas; la orla está flanqueada a cada lado por dos hilos; a continuación encontramos en las bandas horizontales una entrecalle dividida en dos partes por dos hilos, y una entrecalle en las bandas verticales libre de decoración, solo ornamentada por tres pequeños circulillos dobles metálicos en las esquinas; la siguiente orla está flanqueada también por dos hilos a cada lado, y compuesta por dos hileras de rombos anudados en las bandas horizontales, y por una hilera en las bandas verticales; seguidamente se muestra una entrecalle libre de decoración, ornamentada por un circulillo doble metálico en cada una de las esquinas. El rectángulo central está decorado con la repetición de un motivo formado por dos fajas que dividen parejas de aspas cóncavas, todo ello cordiforme; además en el centro del rectángulo aparece una estrella formada por una cinta realizada por cuatro filetes, dos a cada lado, y que en cada esquina o punta aparece un circulillo punteado de piel, posiblemente coloreado; el interior de la estrella está relleno de un círculo aspado, y en el centro, formando un rombo, aparecen ocho circulillos punteados de piel, posiblemente metálicos. Los utensilios empleados han sido hierros sueltos y la técnica decorativa utilizada ha sido el gofrado. El lomo carece de decoración al haberse perdido la piel original. Los broches, manecillas y puntas de metal son nuevos.

El estado de conservación ${ }^{7}$ de la obra era pésimo, presentaba suciedad general, más intensa en los bordes y ángulos inferiores de los folios; sus cortes estaban muy sucios por el polvo con signos de oxidación; también hay zonas perdidas en las guardas y rozaduras en la primera y última hoja; los bordes externos presentaban un intenso amarilleamiento; en muchas hojas aparece en la parte inferior un suplemento de pergamino para subsanar la diferencia de tamaño.

En cuanto a las tintas se distinguen dos técnicas manuscritas, la caligráfica y la pictórica, ambas en buen estado, en general, aunque la primera muestra pequeñas zonas desprendidas del soporte; las tintas son metaloácidas, presentado empalidecimiento al comienzo y al final del libro; en algunas hojas (p. ej. pp. 108, 111, etc.) la tinta roja está corrida; las miniaturas, de gran calidad, están también en buen estado, aunque alguna de ellas (p. ej. p. 63) aparece descascarillada.

Respecto a la encuadernación se encontraba muy deteriorada. Los diversos factores que han actuado nocivamente en el códice han llegado a alterar la propia estructura proteica de la piel, presentando desecación y falta de consistencia, con ruptura interfibrilar que ocasiona su desprendimiento en forma de polvillo; tanto la cubierta superior como la inferior contenían mucha suciedad, manchas, rozaduras, zonas levantadas o perdidas, especialmente en los bordes y en la práctica totalidad del lomo; la flor de la piel estaba perdida en un tanto por ciento muy elevado; el lomo casi había desaparecido, manteniéndose restos de un tejuelo de papel, en el que no queda nada del texto; los nervios aparecían desprendidos y separados de la tapa anterior; las tapas de madera presentaban pequeñas zonas perdidas; los bordes y las esquinas contenían numerosas rozaduras con zonas astilladas; el cosido de los cuadernillos presentaba roturas en diversos puntos; los cierres de metal se presentaban con la pérdida de las puntas de metal y las correíllas de piel; las placas metálicas aparecían sucias, oxidadas y rayadas.

El proceso de restauración consistió en los siguientes pasos:

- Se realizó el análisis del códice en el que se identificaron las características y propiedades que lo formaban como la estabilidad y adherencia de tintas y pigmentos, así como la medición de la acidez del pergamino.

\footnotetext{
${ }^{7}$ La obra ha sido restaurada en el Real Monasterio de San Pelayo de Oviedo por las monjas Benedictinas, y la descripción de los diferentes procesos de restauración han sido extraída del informe entregado a la biblioteca de la Catedral de Toledo.
} 
- Se identificaron las alteraciones que presentaba y las posibles causas que las originaron.

- Se emitió un diagnóstico que permitió determinar el tratamiento más adecuado.

En un principio se realizó una limpieza, hidratación, solución de roturas y desgarros, consolidación de zonas perdidas y aislamiento del pergamino, así como la limpieza y tratamiento de la piel hasta lograr una hidratación satisfactoria. Con las tapas ya preparadas, donde se reintegraron sus zonas perdidas con pasta de madera sintética, se procedió a la encuadernación del libro con una nueva piel de cabra de un tono semejante al original; sobre esta base de piel se adhirió la piel primitiva, debidamente rebajada por los bordes para su integración, marcando seguidamente los nervios del lomo con líneas gofradas. También se limpiaron las piezas metálicas que se conservaban y se reconstruyeron las pérdidas copiando el diseño de las ya existentes, aunque con una tonalidad y textura diferentes para diferenciarse de las originales; se realizaron nuevamente las correíllas.

\section{ENCUADERNACIONES CON BASTONCILLOS CURVOS Y RECTOS Y ESES INCLINADAS}

Continuando con las encuadernaciones toledanas con similares características decorativas, las siguientes cuatro fueron realizadas en talleres toledanos en la segunda mitad del siglo XV, aunque no podemos asegurar si salieron de un mismo taller o fueron realizadas por un mismo encuadernador. En estas imágenes se puede observar como varias estructuras decorativas son muy similares y coinciden en el empleo de los mismos motivos decorativos, siendo un esquema mucho más elaborado que las encuadernaciones de la primera mitad del siglo XV.

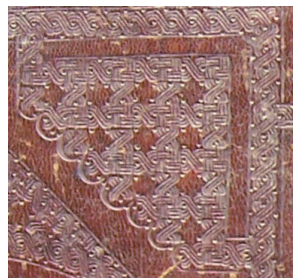

Fig. 54. BCT 11-9 y 14-16.

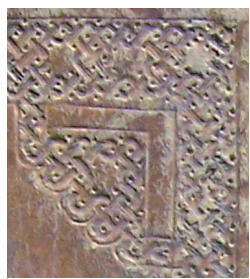

Fig. 55. BCT $11-10$.
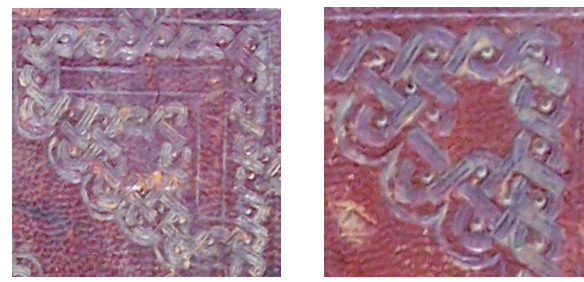

Figs. 56 y 57 . ВCT $94-17$ Tapa posterior y anterior.

El primer volumen contiene la obra manuscrita del siglo XV del papa Gregorio I titulada Super septem Psalmos Paenitentiales. De novem penis inferni et septem beatitudinibus paradisi. Tractatus asceticus. Sus dimensiones son 315 x 228 x 50 mm., pertenece al Antiguo fondo Toledano y su signatura es BCT 11-98.

\footnotetext{
${ }^{8}$ Esta encuadernación formó parte de la exposición Las encuadernaciones artísticas de la Catedral de Toledo, celebrada en la Capilla de Reyes Nuevos de la Catedral entre el 10 de junio al 30 de septiembre de 2009.
} 
Las tapas son de madera recubiertas de piel de color marrón, al igual que el lomo; las guardas y las hojas de respeto son de papel verjurado crema con filigrana con la imagen de una cabeza de toro con una corona real entre los cuernos; los nervios son de tiras de badana curtida al alumbre; el núcleo de las cabezadas es de tiras de badana curtida al alumbre junto a pequeños cordoncillos, todo ello bordado con hilos de colores rojo y amarillo; los entrenervios están recubiertos por papel verjurado con inscripciones en tinta; aparecen restos de broches de metal en la delantera de la tapa posterior.

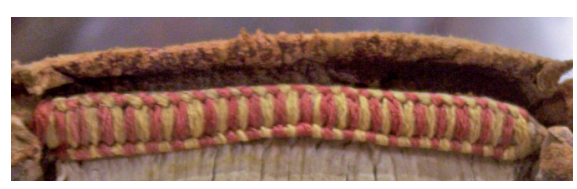

Fig. 58. Cabezada bicolor.

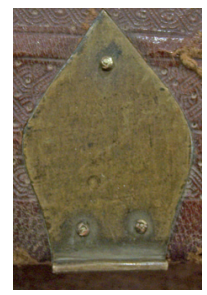

Fig. 59. Broche con forma de punta de lanza

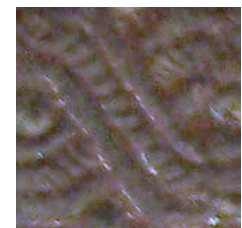

Fig. 60. Eses inclinadas cordiformes cruzadas.

Las tapas están unidas al cuerpo del libro por tiras de badana curtida al alumbre; el cosido está formado por cuatro nervios hendidos a punto seguido; el lomo está redondeado; las cabezadas, realizadas manualmente, están unidas a las tapas y a los cuadernillos.

La estructura de las tapas es simétrica y se compone de tres orlas exteriores, un hexágono y un círculo central. La decoración de inicia con un encuadramiento formado por la repetición de eses inclinadas cordiformes que se entrecruzan formando un aspa; la segunda orla está formada también por el mismo motivo de eses inclinadas cordiformes entrecruzadas, apareciendo en las cuatro esquinas de forma horizontal en la zona cercana a la delantera y lomo, y de forma vertical en la zona cercana a la cabeza y pie; las partes centrales de la orla están decoradas con el mismo motivo, pero la distribución del motivo varía, intercalando dos hierros en forma vertical seguidos de otros dos en forma horizontal, haciendo así más ancha la orla; el tercer encuadramiento está formado, como el primero, por la repetición de eses inclinadas cordiformes, con pequeños puntos a su alrededor estampados en forma horizontal en la cabeza y pie, y en forma vertical en la delantera y en la zona cercana al lomo. La estructura decorativa central se compone de eses inclinadas cordiformes que forman crucetas de lazo en las esquinas, seguida de un primer círculo formado por la repetición de un motivo de eses inclinadas cordiformes entrecruzadas con pequeños puntos a su alrededor estampados en forma horizontal, finalizando en punta en los extremos superior e inferior; el círculo central está ornamentado con los mismos motivos cordiformes que aparecen en las esquinas interiores del rectángulo central, dando lugar a crucetas de lazo cordiformes. Las entrecalles o cintas que dividen las orlas ornamentadas, están libres de decoración, entrecruzándose entre ellas formando pequeñas lacerías en la segunda orla. Los utensilios empleados han sido hierros sueltos gofrados y paletas de hilos estezados para la formación de las cintas. Las guardas y las hojas de respeto están decoradas con una filigrana con la imagen de una cabeza de toro con una corona real entre los cuernos. Los nervios del lomo están decorados con un hilo estezado que divide el nervio hendido. Los entrenervios están recubiertos de papel verjurado con la inscripción en tinta Gre / gorius / super / 7 psal / mos penitente Ms. Las cabezadas están decoradas con el alternado de hilos de seda de colores rojo y amarillo. 


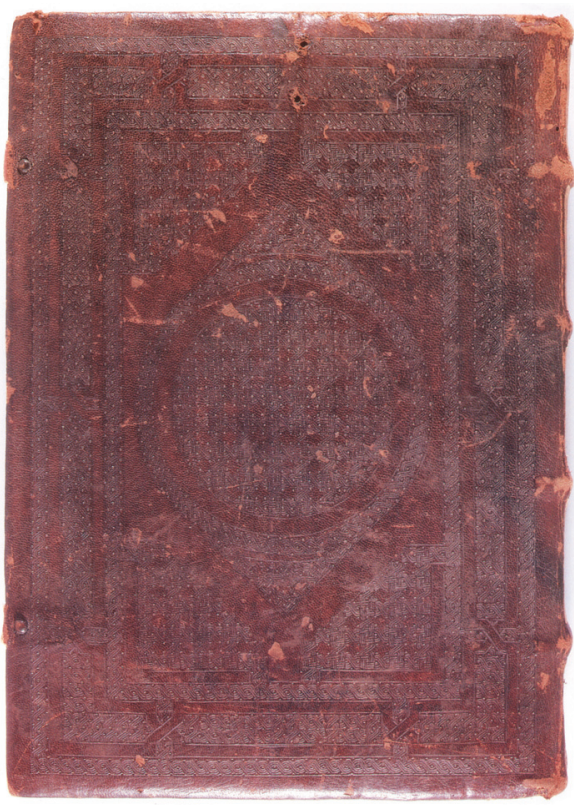

Fig. 61. Tapa anterior.

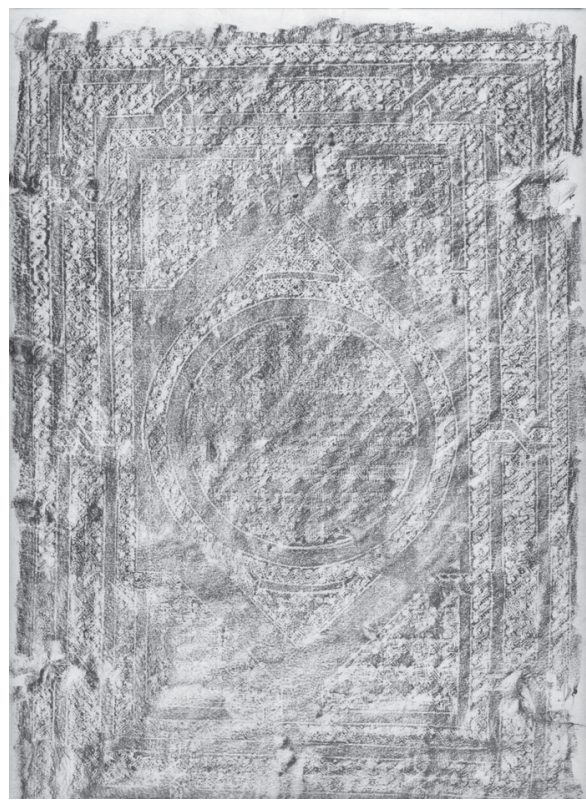

Fig. 62. Frotis de la tapa anterior.

El estado de conservación es aceptable aunque aparecen agujeros en ambas tapas seguramente destinados para sujetar las cadenas.

El segundo volumen contiene la obra manuscrita del Obispo de Hipona titulada Los 13 libros de las Confesiones escritos en Pisa en el año de 1443. Sus dimensiones son 298 x 221 x 38 mm., pertenece al Antiguo fondo Toledano y su signatura es BCT 14-16.

Las tapas son de madera recubiertas de piel de color marrón, al igual que el lomo; las guardas son de pergamino; los nervios son de tiras de piel curtida al alumbre; las cabezadas son de tiras de piel curtida al alumbre y pequeños cordoncillos recubiertos de hilos de colores verde y rojo; los entrenervios están recubiertos por papel verjurado con inscripciones en tinta; los cortes están dorados con pan de oro; los broches son de metal, las manecillas de tela de color rojo con hilos de colores rojo y amarillo y las puntas son de metal.

Las tapas están unidas al libro por tiras de piel curtida al alumbre y con cosido de cinco nervios simples a punto seguido; el lomo está redondeado; las cabezadas, realizadas manualmente, están unidas a los cuadernillos. 


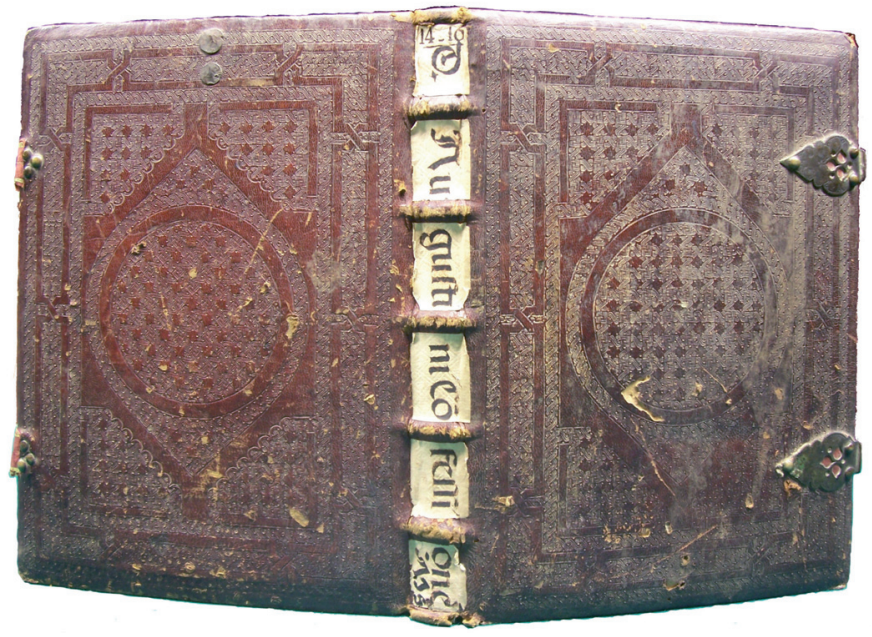

Fig. 63. Tapas y lomo.

La estructura y elementos decorativos, así como los utensilios y técnicas de decoración son iguales a los empleados en la encuadernación con signatura 11-9.

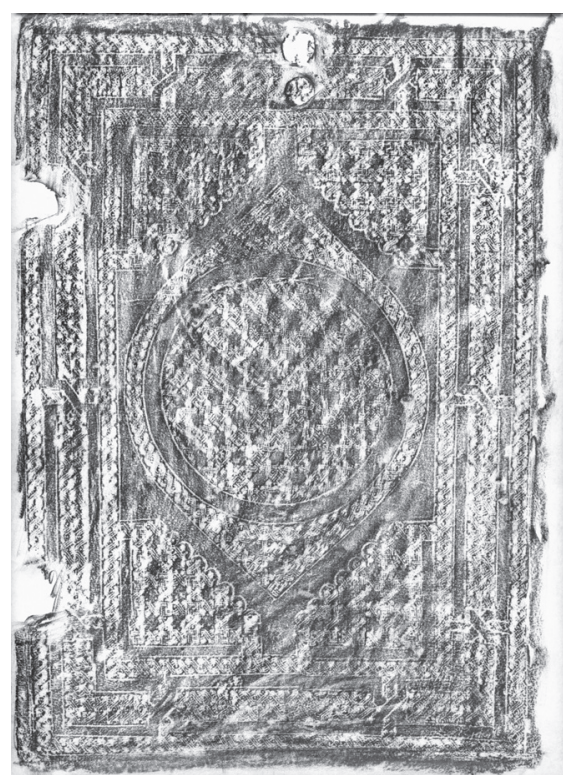

Fig. 64. Frotis de la tapa posterior.

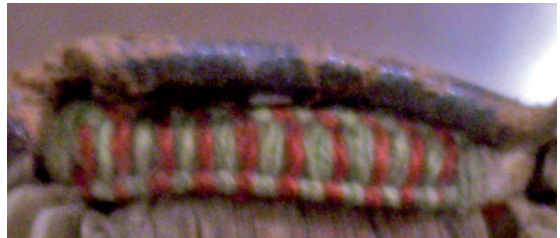

Fig. 65. Cabezada bicolor.

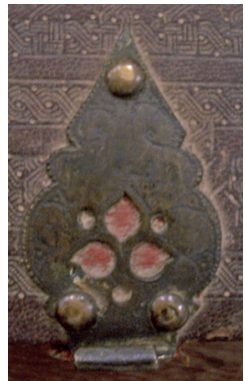

Fig. 66. Broche con forma de árbol labrado.

Fig. 68. Eses inclinadas cordiformes cruzadas.

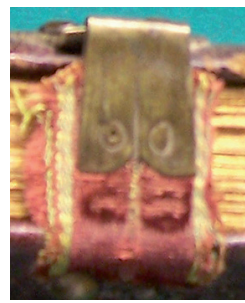

Fig. 67. Manecilla bordada y punta de metal.

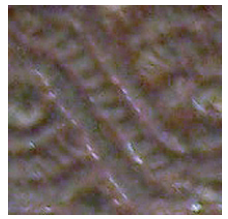


La estructura decorativa está formada por tres orlas exteriores, un hexágono y un círculo central. La decoración se inicia con un encuadramiento formado por una rueda con la repetición de un lazo simple redondeado gofrado. La segunda orla está formada también por un hierro con lazos simples redondeados gofrados, estando el hierro estampado en las cuatro esquinas de forma horizontal en la zona cercana a la delantera y lomo, y vertical en la zona cercana a la cabeza y pie; las partes centrales de la orla están decoradas con el mismo hierro, pero la distribución del motivo varía, intercalando dos hierros en forma vertical seguidos de otros dos en forma horizontal, haciendo así más ancha la orla. El tercer encuadramiento está formado, como el primero, por una rueda de lazo simple redondeado con pequeños puntos a su alrededor estampados en forma horizontal en la cabeza y pie, y en forma vertical en la delantera y zona cercana al lomo. La estructura decorativa central se compone de un primer círculo formado por la repetición de un hierro de lazo simple redondeado con pequeños puntos a su alrededor estampados en forma horizontal, finalizando en punta en los extremos superior e inferior; las esquinas del rectángulo central están decoradas por hierros compuestos de dos elementos simples, un cuadrado y aspas curvas a los lados con pequeños puntos a su alrededor; el círculo central está ornamentado con los mismos motivos que las esquinas interiores del rectángulo central, dando lugar a pequeñas estrellas vacías de decoración. Las entrecalles o cintas que dividen las orlas ornamentadas, están libres de decoración, entrecruzándose entre ellas formando pequeñas lacerías. Los utensilios empleados han sido hierros sueltos gofrados para los motivos mudéjares, una rueda para la tercera orla y la orla exterior y paletas de hilos estezados para la formación de las cintas. Las guardas y hojas de respeto están decoradas con filigrana con la imagen de una cabeza de toro con una corona real entre los cuernos. Los nervios del lomo están decorados con un hilo estezado que divide el nervio hendido. Los entrenervios están recubiertos de papel verjurado con inscripciones en tinta. Las cabezadas están decoradas con el alternado de hilos de seda de colores rojo y verde. Los broches de metal están decorados con tres pequeñas hojas.

La siguiente encuadernación con una decoración en las tapa no es simétrica. La encontramos en el volumen BCT $94-17^{9}$, que contiene una copia manuscrita de Aristóteles, con el título Politicorum libri VIII realizada en el siglo XV al igual que la encuadernación; sus dimensiones son 317 x 217 x $43 \mathrm{~mm}$. y pertenece al Antiguo Fondo Toledano.

Las tapas son de madera biselada recubiertas de piel de color rojizo, al igual que el lomo; las guardas son de pergamino; las hojas de respeto son de papel verjurado y contienen una filigrana; los entrenervios están recubiertos de papel verjurado con inscripciones en tinta; los nervios son de tiras de badana curtida al alumbre; el núcleo de las cabezadas es de tiras de badana curtida al alumbre y un pequeño cordoncillo recubierto de hilos de seda de colores verde y rojo; los broches son de metal y las manecillas de tela roja.

\footnotetext{
${ }^{9}$ Esta encuadernación formó parte de la exposición Las encuadernaciones artísticas de la Catedral de Toledo, celebrada en la Capilla de Reyes Nuevos de la Catedral entre el 10 de junio al 30 de septiembre de 2009.
} 


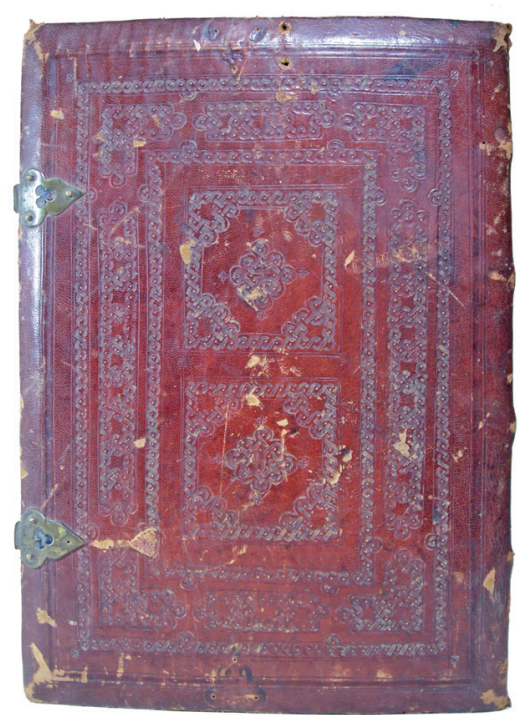

Fig. 69. Tapa posterior.

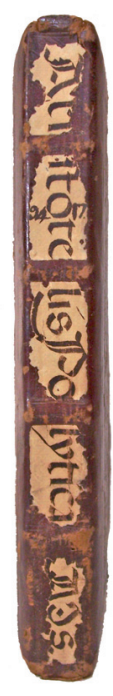

Fig. 70. Lomo.

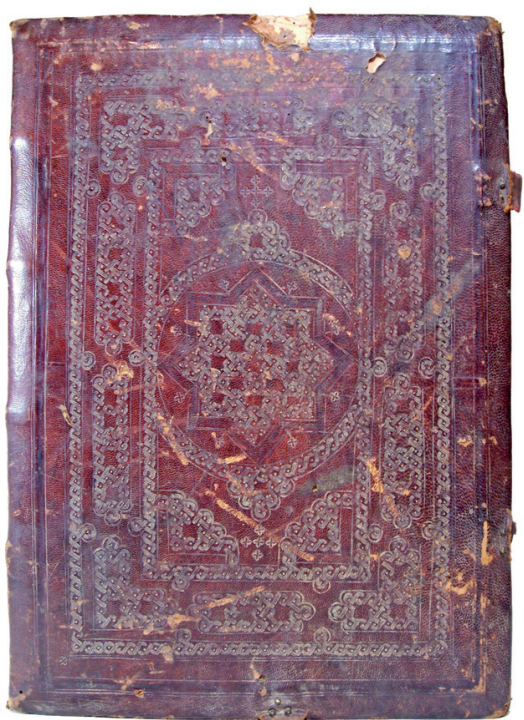

Fig. 71. Tapa anterior.

Las tapas están unidas al libro mediante cuatro nervios hendidos de tiras de badana curtida al alumbre y con un cosido a punto seguido; el lomo es cuadrado; las cabezadas, confeccionadas manualmente, están unidas a las tapas y a los cuadernillos; el corte delantero carece de ceja.

La estructura decorativa de las tapas no es simétrica aunque ambas contienen las mismas tres orlas concéntricas rectangulares y los mismos motivos decorativos entre ellas, con la diferencia que en la tapa anterior aparece una estrella de ocho puntas en el centro y la tapa posterior contiene dos cuadrados con un rombo en el interior de cada uno. La decoración se inicia con dos orlas de eses inclinadas cordiformes, entre las cuales aparecen espacios decorativos ornamentados con eses inclinadas cordiformes que se entrecruzan formando diversas composiciones. En la tapa anterior la parte central está decorada con un círculo formado por eses inclinadas cordiformes, en cuyo interior aparece una estrella de ocho puntas, decorada también por eses inclinadas y bastoncillos curvos y rectos cordiformes que forman composiciones como rombos aspados; en las esquinas del rectángulo central aparecen composiciones formadas por eses inclinadas y bastoncillos rectos y curvos cordiformes, y pequeñas cruces en el resto de los espacios. En la tapa posterior, la decoración interior se compone de dos cuadrados iguales, formados por dos filetes y ornamentados en su interior por una bordura de eses inclinadas cordiformes y bastoncillos curvos y rectos en las esquinas; el centro está decorado por un rombo formado por eses inclinadas y bastoncillos curvos y rectos cordiformes; los espacios interiores de las eses inclinadas están decoradas con un punto. Los utensilios empleados han sido hierros sueltos y la técnica decorativa utilizada ha sido el gofrado. Las cabezadas están decoradas con el alternado de hilos de seda de color verde y rojo. Los broches, de tipo gótico, tienen forma de trébol, con un espacio interior, que también imita una hoja de trébol. 

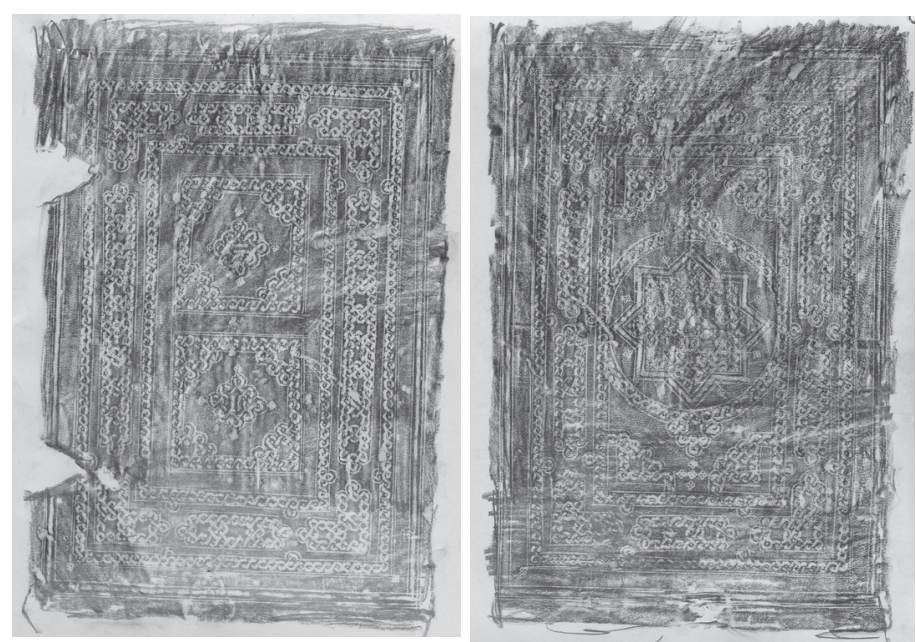

Figs. 72 y 73. Frotis de la tapa anterior y posterior.

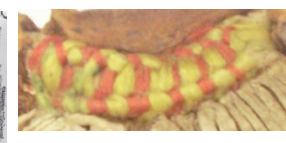

Fig. 74. Cabezada bicolor.

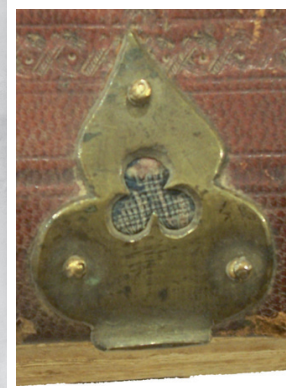

Fig. 75. Broche con forma de hoja de trébol.

El estado de conservación es aceptable con pérdida de las manecillas de tela de los cuatro cierres, dos en el corte delantero, uno en el corte superior y otro en el corte inferior; también hay pérdidas de los broches de metal en el corte superior e inferior y agujeros en la parte superior de la tapa posterior, posiblemente de cadena.

La siguiente encuadernación contiene la obra Salmos penitenciales, copia manuscrita del siglo XV del Papa y Santo Gregorio I. La encuadernación fue realizada en el siglo XV (ca. 1455), pertenece al Antiguo Fondo Toledano, sus dimensiones son 310 x $224 \times 38 \mathrm{~mm}$. y su signatura es BCT $11-10^{10}$.

Las tapas son de madera biselada recubiertas de piel de color marrón, al igual que el lomo; las guardas y las hojas de respeto son de pergamino, aunque algunas de estas últimas son de papel y contienen una filigrana; la guarda es de una pieza y cubre tanto las contratapas como el lomo en su parte interior; los refuerzos interiores son de pergamino y tarlatana; los nervios son de tiras de badana curtida al alumbre; el núcleo de las cabezadas es de tiras de badana curtida al alumbre con dos pequeños cordoncillos bordados de hilos de color rosa y morado; el lomo está recubierto por papel verjurado con inscripciones en tinta; los broches son de metal, la manecilla es de cinta azul bordada y la punta de metal.

Las tapas están unidas al cuerpo del libro mediante tiras de badana curtida al alumbre; el cosido contiene tres nervios sencillos a punto seguido; el lomo está redondeado; las cabezadas realizadas manualmente aparecen unidas a las tapas y a los cuadernillos.

La estructura decorativa de las tapas no es simétrica y está formada por una orla exterior y un círculo central. La decoración de ambas tapas se inicia con un encuadramiento formado por tres hilos, el central más grueso.

${ }^{10}$ Esta encuadernación formó parte de la exposición Las encuadernaciones artísticas de la Catedral de Toledo, celebrada en la Capilla de Reyes Nuevos de la Catedral entre el 10 de junio al 30 de septiembre de 2009. 


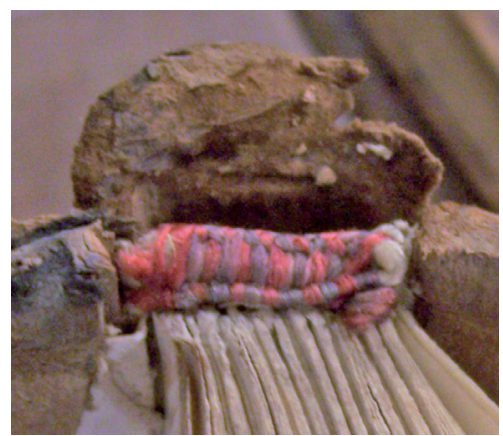

Fig. 76. Cabezada bicolor.

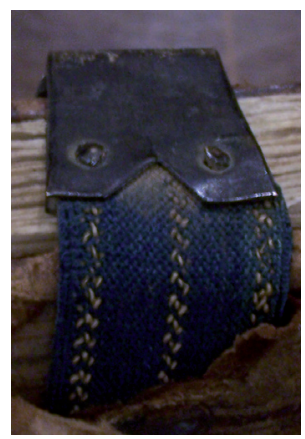

Fig. 77. Manecilla textil y punta de metal.

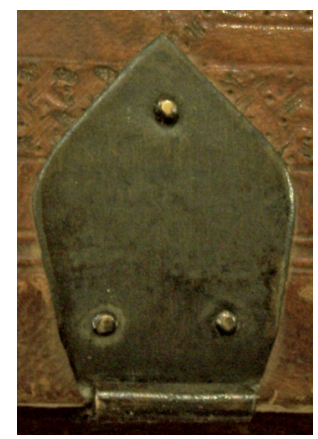

Fig. 78. Broche de metal.

La primera orla está decorada con pequeños hierros mudéjares cordiformes (eses inclinadas, bastoncillos curvos y rectos), que se entrecruzan junto a pequeños puntos, formando un vistoso diseño. Las esquinas interiores del rectángulo central están decoradas también con pequeños hierros mudéjares cordiformes similares a los anteriores.

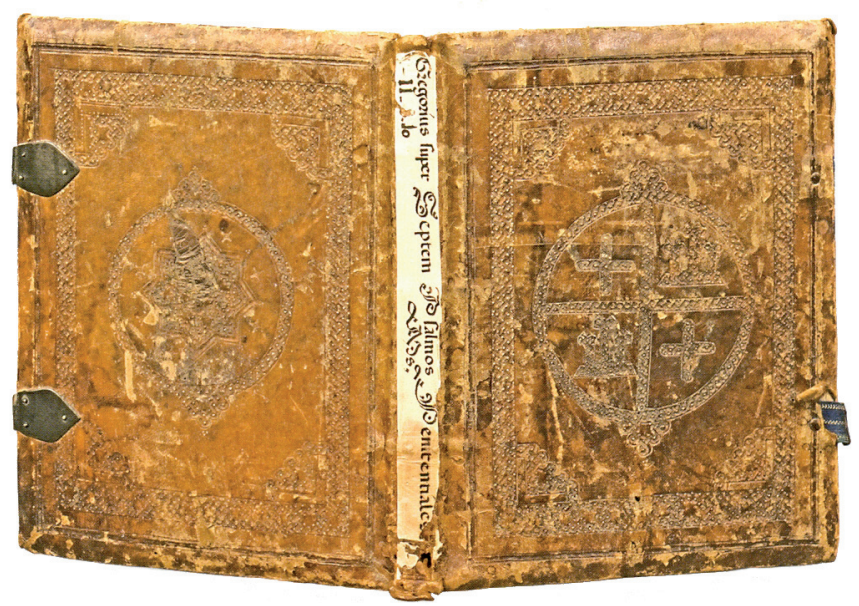

Fig. 79. Tapas y lomo.

El centro de ambas tapas está ornamentado por un círculo formado por dos filetes, entremedias de los cuales se estampan eses inclinadas y pequeños puntos; en la parte superior e inferior del círculo aparece un pequeño triángulo formado por pequeños hierros cordiformes que se entrecruzan. En la tapa anterior, el círculo se divide en cuatro partes mediante la repetición de eses inclinadas flanqueadas por dos hilos, uno a cada lado; en la parte superior izquierda y la inferior derecha se repite una cruz realizada por eses inclinadas; en la parte superior derecha y en la inferior izquierda se re- 
pite un calvario con tres cruces, la central algo más grande, realizada también por eses inclinadas. En la tapa posterior, el interior del círculo central está ornamentado con una estrella de ocho puntas dibujada con tres líneas estezadas, la central más gruesa, con tres pequeños puntos en los vértices más externos y un pequeño rombo de lados cóncavos en el resto de los vértices, la cual contiene en su interior una decoración de pequeños hierros cordiformes que se entrecruzan. Los utensilios empleados han sido hierros mudéjares gofrados y paletas de líneas estezadas. El lomo está recubierto de papel verjurado con inscripciones góticas. El tejuelo contiene la leyenda Gregorius super septem psalmos penitentiales Ms. Los broches son de latón con forma de punta de lanza y la manecilla es de cinta bordada de colores azul y amarillo junto a la punta de metal. Las cabezadas están decoradas con el alternado de hilos de seda de colores rosa y morado. Las guardas carecen de decoración, solo una pequeña inscripción en caracteres góticos en la parte superior de la guarda anterior.

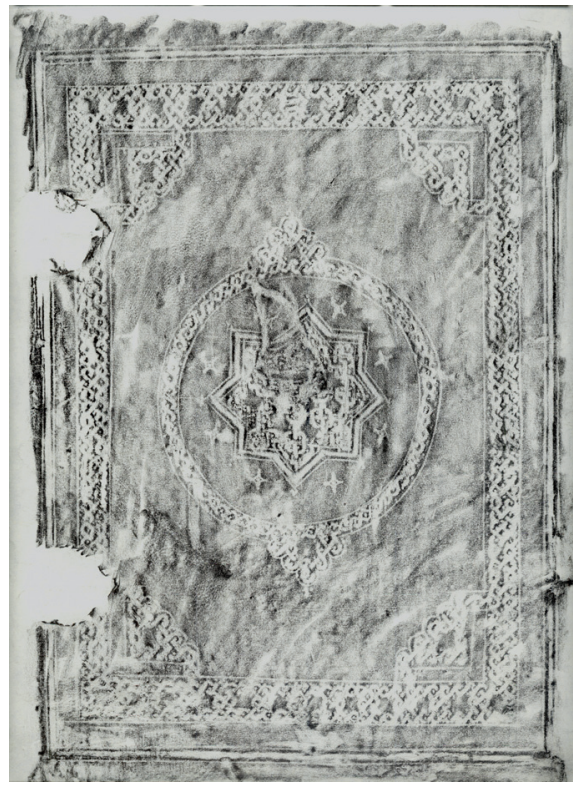

Fig. 80. Frotis de la tapa posterior.

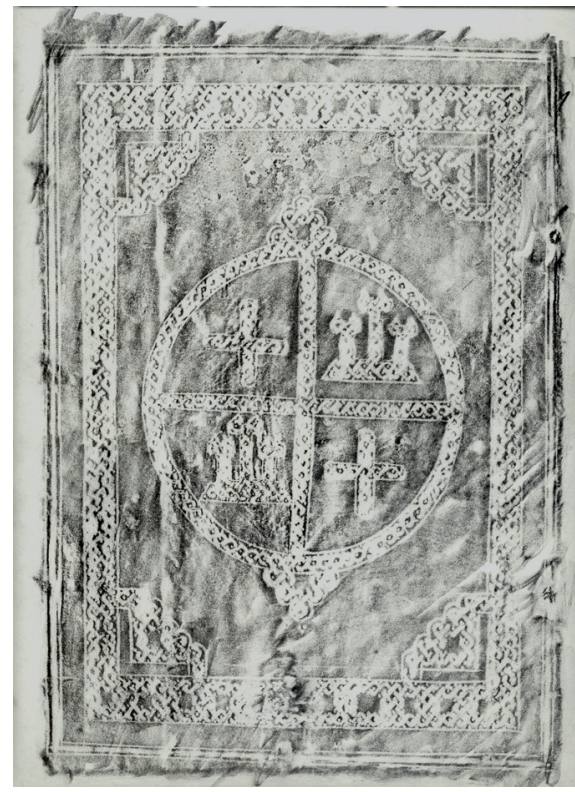

Fig. 81. Frotis de la tapa anterior.

El estado de conservación es bueno con algunas pequeñas pérdidas de piel, numerosas rozaduras y la pérdida de la manecilla bordada superior. 


\section{ENCUADERNACIÓN CON ROMBOS DE LADOS CÓNCAVOS Y LAZOS SIMPLES RECTOS}

El volumen con signatura BCT $35-18^{11}$ contiene un manuscrito con un (Epistolario) del siglo XIII. La obra pertenece al Antiguo Fondo Toledano y en la contraguarda anterior de pergamino aparece el nombre de: Don Johan Perez Lagera. Algunos motivos decorativos, como los rombos de lados cóncavos y los lazos simples redondeados cordiformes, nos indican de que probablemente esta encuadernación sea toledana realizada a finales del siglo XV o primeros del XVI; sus dimensiones son $250 \times 167 \times 47 \mathrm{~mm}$.

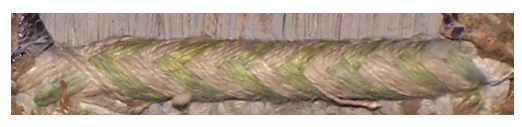

Fig. 82. Cabezada bicolor tipo espiga.

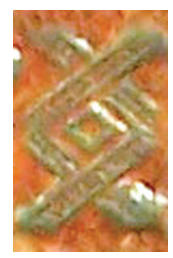

Fig. 83. Lazo simple recto cordiforme.
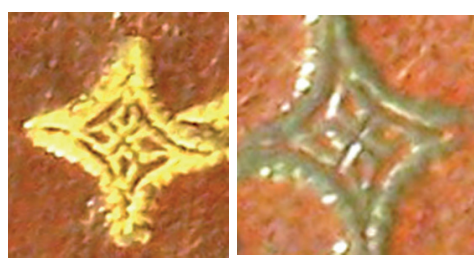

Figs. 84 y 85 . Rombos de lados cóncavos dorados y gofrados.

Las tapas son de madera recubiertas de piel de color marrón rojizo, al igual que el lomo; las guardas y las hojas de respeto son de pergamino; los entrenervios están recubiertos de papel verjurado con inscripciones manuscritas en tinta; los nervios son de tiras de badana curtida al alumbre; el núcleo de las cabezadas es de tiras de badana curtida al alumbre recubierto de hilos de seda de colores marrón y verde; los cortes están dorados con pan de oro.

Las tapas están unidas al libro mediante tres nervios hendidos de tiras de piel y un cosido a punto seguido; el lomo es cuadrado; las cabezadas son simples y están realizadas manualmente, unidas a las tapas y a los cuadernillos, denominadas cabezadas de espiga renacentista, muy populares entre los siglos XV y XVI.

La estructura de las tapas no es simétrica y se compone de una orla concéntrica y un rectángulo central con hierros sueltos dorados y gofrados. La decoración se inicia con grupos de tres pequeños dobles circulillos en la bordura exterior, seguida de una orla de lazos simples en ángulo cordiformes, con una pequeña florecilla en su interior, flanqueada por dos filetes hacia el exterior y por uno en el interior; a continuación aparece un rectángulo central ornamentado por rombos de lados cóncavos que forman dos grandes rombos, uno en la parte superior y otro en la inferior, unidos por otros pequeños rombos de lados cóncavos dorados en el centro del rectángulo. Los utensilios empleados han sido hierros sueltos y las técnicas decorativas utilizadas han sido el gofrado y el dorado. Los nervios están decorados con un filete horizontal gofrado, que acentúan el empleo de nervios hendidos. Las cabezadas están decoradas con el alternado de hilos de seda de colores verde y marrón, en forma de espiga; este tipo de cabezadas era realizado frecuentemente en las encuadernaciones del siglo XV y XVI. Los cortes están dorados con pan de oro y bruñidos.

${ }^{11}$ Esta encuadernación formó parte de la exposición Las encuadernaciones artísticas de la Catedral de Toledo, celebrada en la Capilla de Reyes Nuevos de la Catedral entre el 10 de junio al 30 de septiembre de 2009. 
El estado de conservación de la encuadernación es aceptable con pérdida de las dos manecillas de la delantera de la tapa posterior.

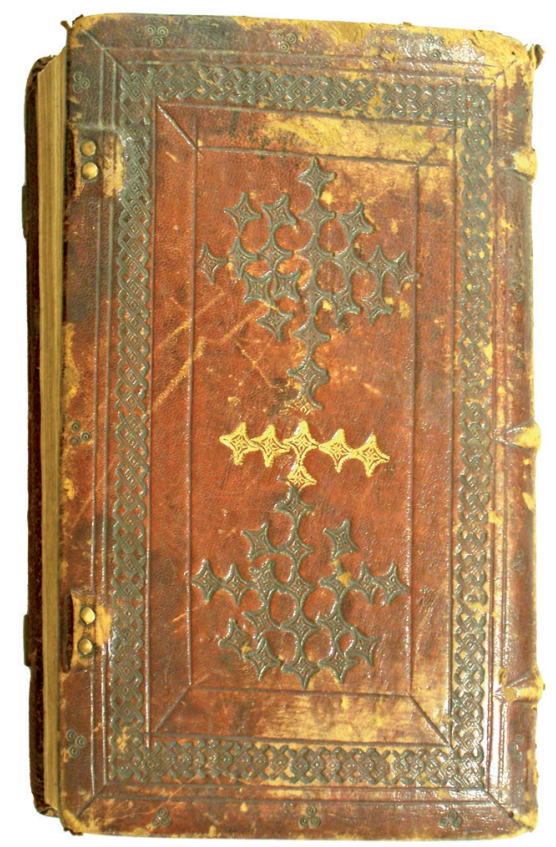

Fig. 86. Tapa posterior.

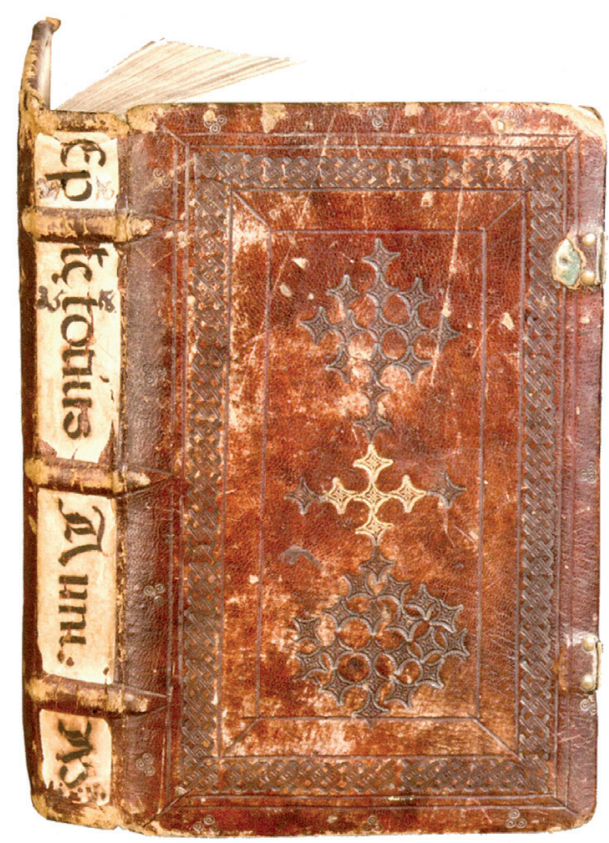

Fig. 87. Tapa anterior y lomo.

\section{CONCLUSIONES}

Como conclusiones finales indicar que se han identificado y descrito los escudos heráldicos de las portadas y guardas de varias obras (sign. 6-26 y 24-4), ayudando a conocer la historia del ejemplar y su procedencia; observando otras encuadernaciones mudéjares realizadas en Toledo en el siglo XV, depositadas en la Biblioteca Nacional de España y en la Biblioteca Regional de Castilla-La Mancha, que contienen las mismas estructuras decorativas y el empleo de los mismos hierros sueltos, y mediante la consulta de los libros de Obra y Fábrica, donde aparecen anotaciones sobre pagos a encuadernadores durante el siglo XV, aunque al no indicarse la obra encuadernada no podemos determinar la autoría de las encuadernaciones, y junto a la carencia en la Catedral de scriptorium, se demuestra la existencia de talleres que trabajaron para el clero en esa época; no podemos determinar quiénes fueron los encuadernadores responsables, ni siquiera si salieron del mismo taller, pero sí que se realizaron en la misma época y en la ciudad de Toledo. En cuanto a los materiales empleados en la construcción, todas las encuadernaciones contienen tapas de madera y las pieles son de cabra y de becerro de color avellana, excepto algunas recubiertas de piel curtida al alumbre (sign. 6-26) y otras teñidas de color marrón oscuro (sign. 42-40) y tonos rojizos (sign. 11-9, 14-16 y 94-17); la técnica de estampación siempre ha sido el gofrado 
excepto en el último ejemplo (sign. 35-18); las cabezadas están realizadas con tiras de piel curtida al alumbre y dos cordoncillos, uno superior y otro inferior, recubiertas de dos hilos, en su mayoría de color rojo y amarillo; los nervios sueles ser hendidos de tiras de piel curtida al alumbre y el cosido del tipo a punto seguido. Que las tapas sean de madera nos indica que son encuadernaciones probablemente realizadas en la primera mitad del siglo XV ya que el cartón, como soporte de las tapas, será muy utilizado ya en el último cuarto del siglo XV y primeros del XVI. También se puede observar la evolución en los esquemas decorativos, comenzando a primeros del siglo $\mathrm{XV}$ con esquemas más simples basados en diferentes encuadramientos realizados con uno, dos o tres motivos simples y una estrellas en el centro, pasando a la segunda mitad del siglo a esquemas decorativos mucho más elaborados, con lacerías, composiciones de hierros, incluso con estructuras diferentes en cada tapa.

\section{BIBLIOGRAFÍA CITADA}

Ainaud Lasarte, Josep María, Encuadernación, “Ars Hispaniae” 18 (1962), pp. 321 344.

Álvaro Zamora, María Isabel, Encuadernaciones mudéjares, “Artigrama” 23 (2008), pp. 445-481.

Carpallo Bautista, Antonio, Estudio de las encuadernaciones del siglo XV de la Biblioteca Complutense, "Gutenberg Jahrbuch" (2009), pp. 315-345.

Carpallo Bautista, Antonio; Burgos Bordonau, Esther, Las encuadernaciones mudéjares de lacería con motivos centrales en la Catedral de Toledo, "Anales de Documentación” 15/1 (2012), pp. 1-30.

Hueso Rolland, Francisco, Exposición de encuadernaciones españolas: siglos XII al XIX, Madrid, Sociedad Española de Amigos del Arte, 1934.

López Serrano, Matilde, La encuadernación española: breve historia, Madrid, ANABA, 1972.

Méndez, Víctor, Encuadernación mudéjar: desarrollo geométrico de la lacería, "Noticias bibliográficas" 40 (1994), pp. 5-11.

Méndez Aparicio, Julia, La encuadernación mudéjar, en Encuadernaciones españolas en la Biblioteca Nacional, Madrid, Biblioteca Nacional, 1992, pp. 17-30.

Miquel y Planas, Ramón, Restauración del Arte hispano-árabe en la decoración exterior de los libros, Barcelona, Miquel Rius, 1913.

Fecha de recepción del artículo: marzo 2011

Fecha de aceptación y versión final: agosto 2011 
